\title{
Adhesion force spectroscopy with nanostructured colloidal probes reveals nanotopography-dependent early mechanotransductive interactions at the cell membrane level
}

M. Chighizola, A. Previdi, T. Dini, C. Piazzoni, C. Lenardi, P. Milani, C. Schulte* and A. Podestä

C.I.Ma.I.Na. and Dipartimento di Fisica "Aldo Pontremoli", Università degli Studi di Milano, via Celoria 16, 20133 Milan, Italy.

${ }^{*}$ Corresponding authors:

alessandro.podesta@mi.infn.it; carsten.schulte@unimi.it 


\section{ABSTRACT}

Mechanosensing, the ability of cells to perceive and interpret the microenvironmental biophysical cues (such as the nanotopography), impacts strongly on cellular behaviour through mechanotransductive processes and signalling. These events are predominantly mediated by integrins, the principal cellular adhesion receptors located at the cell/extracellular matrix (ECM) interface.

Because of the typical piconewton force range and nanometre length scale of mechanotransductive interactions, achieving a detailed understanding of the spatiotemporal dynamics occurring at the cell/microenvironment interface is challenging; sophisticated interdisciplinary methodologies are required. Moreover, an accurate control over the nanotopographical features of the microenvironment is essential, in order to systematically investigate and precisely assess the influence of the different nanotopographical motifs on the mechanotransductive process.

In this framework, we were able to study and quantify the impact of microenvironmental nanotopography on early cellular adhesion events by means of adhesion force spectroscopy based on innovative colloidal probes mimicking the nanotopography of natural ECMs.

These probes provided the opportunity to detect nanotopography-specific modulations of the molecular force loading dynamics and integrin clustering at the level of single binding events, in the critical time window of nascent adhesion formation. Following this approach, we found that the nanotopographical features are responsible for an excessive force loading in single adhesion sites after $20-60 \mathrm{~s}$ of interaction, causing a drop in the number of adhesion sites. However, by manganese treatment we demonstrated that the availability of activated integrins is a critical regulatory factor for these nanotopography-dependent dynamics.

\section{KEYWORDS}

Mechanosensing, mechanotransduction, mechanobiology, cell adhesion, nanotopography, nanostructured materials, cell microenvironment, extracellular matrix, atomic force microscopy, colloidal probes, adhesion force spectroscopy, integrin binding, adhesion complexes. 


\section{INTRODUCTION}

A complex crosstalk between cells and their microenvironment, i.e. the extracellular matrix (ECM), governs the development and maintenance of multicellular tissues. The biophysical properties of the microenvironment were therein identified as critical factors for the regulation of many cellular responses, such as proliferation, migration, and differentiation. The ECM is a complex meshwork of intertwined macromolecules (with protein and sugar components) characterised by the presence of fibrillary and reticular structures, pores and asperities at the nanoscale. The configurations can be relatively ordered, as e.g. in fibrillary collagen-dominated ECM, or instead rather disordered, as in basement membranes or brain ECM. However, on the local nanoscale level often irregularities, anisotropies and density gradients are present ${ }^{1-6}$.

In recent years, it became evident that mechanical stimuli of the ECM, such as rigidity and/or spatial organisation and dimensionality of adhesion sites (e.g., in terms of geometry and topography), alter intrinsic cellular properties, such as the actin cytoskeletal organisation/mechanics and the signalling status ${ }^{7-10}$.The intricate processes through which the cell perceives and reacts to mechanical and structural stimuli in its microenvironment were termed mechanosensing and mechanotransduction $^{11-18}$.

Mechanotransductive processes are involved in virtually all aspects of the cellular life and tissue organisation ${ }^{11-19}$ and aberrations in components that participate to mechanosensing and mechanotransduction have been linked to various diseases, in particular in cancer and metastasis. A detailed comprehension of how biophysical ECM characteristics modulate mechanotransduction would promote new approaches for treatments of diseases, drug therapies or diagnostic approaches, exploiting and targeting identified mechanotransductive key regulators or structures ${ }^{11,20-25}$.

Cells sense the biophysical microenvironmental information at the nanoscale, and the nanotopography emerged as a crucial parameter in the regulation of mechanotransductive processes and signalling ${ }^{7-9,26-29}$. The mechanotransductive pathway is primarily mediated by specific transmembrane proteins, called integrins, and modulated by the extent to which these integrins cluster together into integrin adhesion complexes (IACs) and mature into bigger structures, such as focal complexes and focal adhesions (FAs). The extent of integrin clustering and FA maturation, in turn, depends on the force loading within the so-called molecular clutches of nascent adhesions, i.e. the initial connection of the ECM-binding integrins to forces generated by the actin cytoskeleton via adaptor proteins (in particular talin and vinculin). The spatial organisation of integrin adhesion sites (ligands) exerts a fundamental influence on the integrin clustering and eventually on cellular behaviour and responses. These effects are mediated in particular through the principal elements of 
mechanotransductive signalling, such as RhoGTPases, the actin cytoskeleton and mechanosensitive transcription factors (e.g., YAP) ${ }^{11-19}$.

However, a better understanding and quantification of the dynamics in the cell/microenvironment interface and the force development in the early steps of cellular mechanosensing in response to different topographical stimuli is required. In particular, although the presence of nanotopographical disorder (due to the impact on the spatial distribution of integrin ligands) has been shown to have a strong influence on protein adsorption, cell adhesion, integrin clustering and differentiation ${ }^{7,30,31}$, the systematic characterisation of the influence of disordered configurations with different nanoscale three-dimensional features is still in its infancy.

To unravel the molecular mechanisms of cellular mechanosensing and the mechanotransductive responses it provokes in the cells, versatile biophysical approaches are essential $^{10,17,29,32-39}$. Smart biomaterials with complex structural architectures and/or tuneable physical properties are needed to create controllable cellular microenvironments that mimic the in vivo ECM situation ${ }^{7,29,32,34,35}$. In addition, sophisticated techniques are required that enable the mapping of mechanobiologically relevant alterations in cells $\mathrm{s}^{17,33,36}$.

In this context, atomic force microscopy (AFM) represents a powerful tool due to its capacity to allow an accurate probing of cell surfaces, determining cellular mechanical properties ${ }^{40-}$ 43 (and mechanotransduction-related alterations ${ }^{44-46}$ ), and measuring adhesion forces down to the single-molecule contribution ${ }^{36}$. The standard techniques used to test the cellular adhesion properties are Single-Molecule Force Spectroscopy $(\mathrm{SMFS})^{47}$ and Single-Cell Force Spectroscopy $(\mathrm{SCFS})^{48},{ }^{49}$. SMFS consists in a functionalisation of the AFM probe (e.g., coating with ECM proteins) in order to permit the interaction with specific transmembrane proteins. SCFS instead uses the cell itself as a probe (attached to the cantilever) that interacts with the substrates of interest (including other cells).

SCFS has been widely used to study in detail the cooperative action of integrins in early cellular adhesion to fibronectin or collagen ${ }^{50-52}$ and their connection to internal cellular biochemical signalling ${ }^{53}$. This technique has furthermore been exploited to test the biocompatibility of materials for implants in orthopaedic surgery ${ }^{54}$, or the role of ligand spacing in the cell adhesion using substrates decorated with suitably functionalised nanoparticles, separating integrin ligands with different specific distances ${ }^{55,56}$. A limitation of SCFS, as explained in detail by Naganuma ${ }^{57}$, is that the actual contact area between the cell and the substrates cannot be measured. As a matter of fact, the cell, once captured and immobilised on the tipless cantilever, will evolve its own adhesion on the probe itself, changing its morphology during time and with it the adhesion properties. These 
dynamics will introduce a bias in the force spectroscopy experiment and, since different cells behave differently, make results less comparable between each other.

To address these issues, we propose a reversal of the conventional SCFS approach. Our novel strategy for the study of early mechanotransductive interactions at the cell membrane level is based on the use of functionalised colloidal probes (CPs) mimicking the peculiar nanoscale topographical features of in vivo ECM for force spectroscopy experiments on living cells. The probes represent the source for the mechanical cues regulating the cascade of the mechanotransductive events. By inverting the typical cell-microenvironment interaction geometry (Figure 1), we take in particular control over the cell/substrate contact area, and obtain a more accurate assessment of the forces and molecular interactions that develop at the cell membrane during the early mechanotransductive events.

Our technological approach for the fabrication of nanotopographical surfaces consists in growing a cluster-assembled thin film of nanostructured zirconium oxide (ns- $\mathrm{ZrO}_{2}$, zirconia) with disordered, yet controlled, topographical features by means of supersonic cluster beam deposition $(\mathrm{SCBD})^{58-60}$. Zirconia is a biocompatible material used in various clinical application, particularly for its chemical inertness and structural properties ${ }^{61}$. SCBD is an additive technique and the disordered surface morphology of the deposited films is characterised by nanoscale roughness and other morphological parameters, like the surface area or the correlation length, which can be accurately tuned and reproduced by controlling the film thickness through the deposition time ${ }^{62}$.

The obtained disordered nanostructured films possess nanotopographical features that resemble those that can be observed in in vivo ECM (e.g. in basement membranes or in the brain ${ }^{5,6}$ ) and with nano-3D configurations (in terms of asperity dimensionality and distances) that have a potential to modulate integrin-dependent mechanotransductive processes and signalling $30,44,58,63-67$ (Figure 1a). Indeed, also in those ECMs whose structure is dominated by fibrillar features, there are often irregularities at the nanoscale, e.g. in regards to distances and heights of fibres or in the pore sizes of reticular, crosslinked structures, which are well represented by the nanotopographical features of the $\mathrm{ns}-\mathrm{ZrO}_{2}{ }^{6,44}$.

Using these nanostructured thin films as substrates (Figure 1a), we have recently shown that the interaction of cells, in particular neuronal cells, with the nanotopographical features, impacts decisively on mechanotransductively relevant events, such as FA maturation, cytoskeletal organisation/mechanics and integrin signalling, as well as the cellular program and differentiative behaviour $44,58,63,64,68$. 


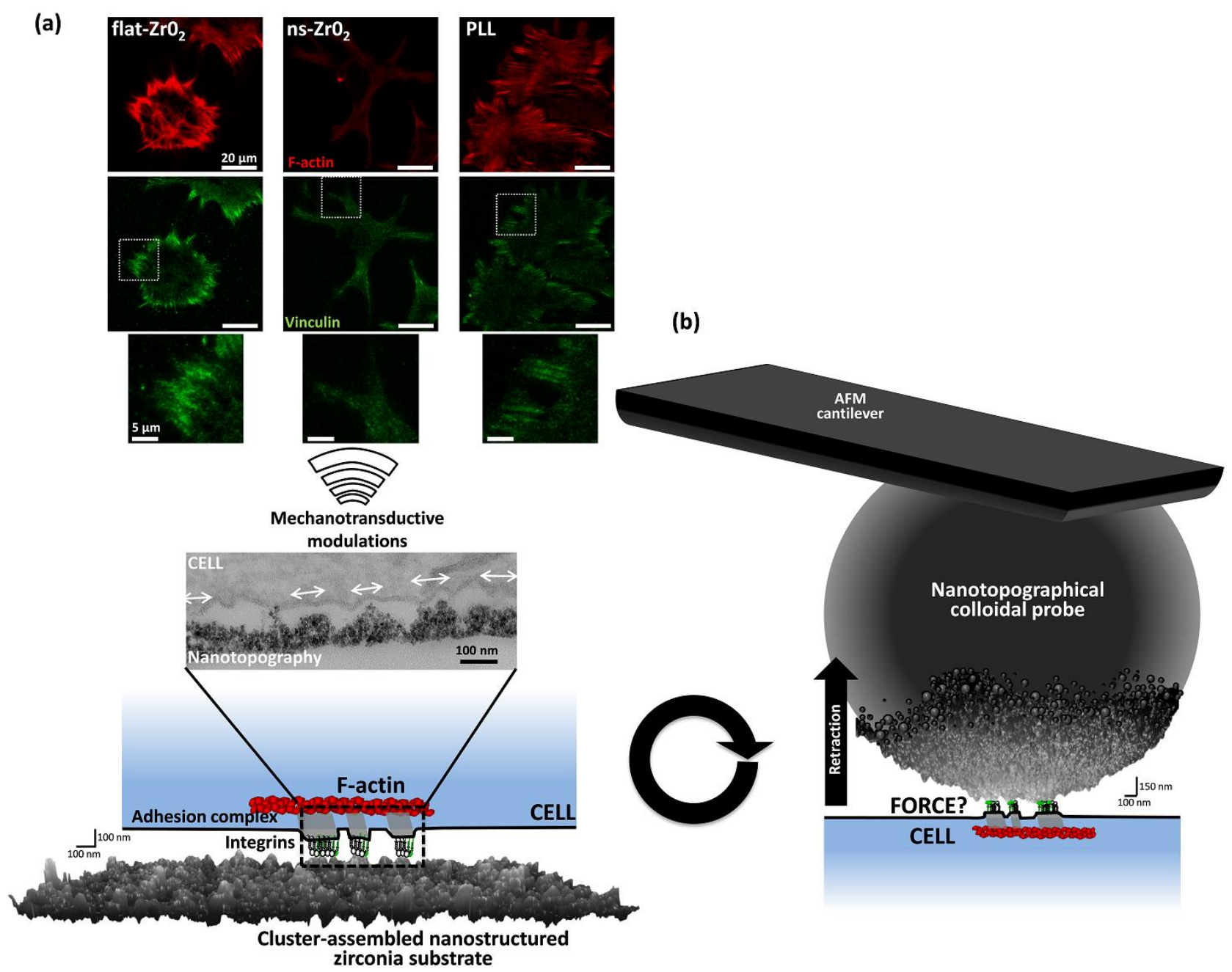

Figure 1. (a) The scheme at the bottom left illustrates the conventional approach used to study the impact of nanotopographical features on mechanotransductive processes. The image inset shows a transmission electron microscopy (TEM) image of an interaction sites between a PC12 cell and the asperities of cluster-assembled ECM-mimicking nanotopographical zirconia substrate (indicated by the white arrows) with an rms roughness $r_{q}=15 \mathrm{~nm}\left(\mathrm{~ns}-\mathrm{ZrO}_{2}\right)$, for which we have shown that it induces mechanotransductive modulations ${ }^{44}$. The immunofluorescence (IF) images in the panel above (in green, total internal reflection recordings of vinculin staining; in red, epifluorescence recordings of the actin filaments marked by phalloidin staining) demonstrate that, after 4 hours of interaction on the nanotopographical $n s-\mathrm{ZrO}_{2}$ substrate, only small punctate focal complex size adhesion sites formed and stress fibres were absent, whereas on the flat zirconia (flat- $\left.\mathrm{ZrO}_{2}\right)$ and PLL-coated glass (PLL) substrates, focal adhesions and stress fibres are present ${ }^{44}$. (b) Schematic illustration of the approach to measure adhesion forces to colloidal probes with a nanotopographical surface $\left(r_{q}=15 \mathrm{~nm}\right)$ produced by SCBD (the scale bars close to the 
nanostructured surfaces refer only to the nanotopography, other graphical icons are symbolic and not in scale). TEM and IF images in (a) were adapted from Schulte et al. ${ }^{44}$.

Instead of plating the cells on the nanostructured substrates, here we exploited the nanotopographical colloidal probes (nt-CPs) to stimulate the cells and to characterise the interfacial integrin dynamics by means of adhesion force spectroscopy (Figure 1b). Compared to our previous experiments, this approach provided access to phenomena that occur at the cell-microenvironment interface that would otherwise be buried below the cell body.

To date, only few protocols have been developed to functionalise AFM probe surfaces either with ECM proteins, like collagens, laminins, or cellulose nanofibers ${ }^{69,70}$ or with nanoparticles ${ }^{71-73}$. In the former case, natural biomaterials were typically deposited onto CPs, but poor or null control over the nanoscale topography was possible. In the latter case, AFM standard sharp tips were decorated with nanoparticles in order to study their interaction with cells; in other experiments the AFM tip apex was used to model a single nanoparticle ${ }^{74}$. Our nt-CPs were instead used to study the early steps of the cell adhesion to an ECM-mimicking nanotopography with the sensitivity of adhesion force spectroscopy measurements. Following this innovative approach, we were able to follow the temporal evolution of early integrin-related adhesion events at the interface between the cell and a nanotopographical microenvironment at the level of single adhesion events and piconewton force range. To our best knowledge, in this framework of cell/nanotopography interaction such a resolution has not been achieved to date.

\section{MATERIALS AND METHODS}

\subsection{Fabrication and calibration of the colloidal probes}

Fabrication of the colloidal probe. The procedure for the fabrication of colloidal probes is based on the approach described in detail in Ref. ${ }^{75}$. Borosilicate glass spheres (Thermo Fisher Scientific), with radius $\mathrm{R}=10 \pm 1 \mu \mathrm{m}$, are first cleaned to remove surface contaminants. The cleaning procedure consists in three sequential 60 seconds centrifugations $(10.000 \mathrm{rpm})$ in a $1: 1$ water and ethanol solutions, carefully replacing the old with new solution after each centrifugation. The cleaned spheres are then dispersed in toluene and deposited on a microscopy glass slide coated with a thin Au film (with thickness $100 \mathrm{~nm}$ ) deposited by sputtering. The Au film is used to reduce the capillary force between the sphere and the substrates with respect to that between the sphere and a tipless cantilever ${ }^{75}$ (Micromash HQ:CSC38/tipless/no Al, force constant $k=0.02-0.03 \mathrm{~N} / \mathrm{m}$ ). The capture of the sphere by the cantilever is done using the XY motorised stage of the AFM microscope, integrated in the optical inverted microscope. The probe is then transferred in a pre- 
heated high-temperature oven and kept for 2 hours at $780^{\circ} \mathrm{C}$. This temperature is slightly below the softening point of borosilicate glass, which is qualitatively defined as the temperature at which a solid object begins collapsing under its own weight. After two hours, the microsphere is covalently attached to the cantilever. Due to the monolithic character of the resulting $\mathrm{CP}$, any gold residue, as well as other contaminants, can be effectively removed by washing the probe in aqua regia (a mixture of nitric and hydrochloric acids, in a molar ratio of 1:3), or any other aggressive solution.

Determination of the probe radius. The characterisation of the $\mathrm{CP}$ radius is performed by AFM reverse imaging of the probe on a spiked grating (TGT1, Tips Nano), as detailed in Ref. ${ }^{75}$. Upon scanning the $\mathrm{CP}$ on the spiked grating, hundreds of independent replicas of the probe apical region are obtained. From the measured geometrical properties (like the volume V and the height $h$ ) it is possible to determine the value of the radius $\mathrm{R}$ by fitting a spherical cap model $V=\frac{\pi}{3} h^{2}(3 R-h)$ to the data. The evaluated probe radius has an accuracy as good as $1 \%$.

Calibration of the cantilever spring constant. The spring constant is calibrated using the thermal noise method ${ }^{76,77}$ where a special correction factor is applied in order to take into account the relevant dimension and mass of the glass sphere ${ }^{78}$. For large CPs, the conditions that both dimension and mass of the sphere are small compared to length and mass of the cantilever are not always satisfied. Since the mass of the microsphere scales with the cube of the radius $R$, beads with radii larger than $5 \mu \mathrm{m}$ possess a mass comparable to the mass of the cantilever, and in some cases, especially with stiffer, shorter cantilevers, even larger. These conditions lead to the failure of the assumption that the mass of the cantilever is uniformly distributed along its length, resulting in an underestimation of the spring constant.

According to Ref. ${ }^{78}$, it is possible to correct the apparent spring constant $K_{0}^{\text {th }}$ measured by the thermal noise method using the formula:

$$
K^{t h}=\frac{\beta}{\beta_{0}} K_{0}^{t h}
$$

where $K^{\text {th }}$ is the corrected spring constant, while for rectangular cantilevers $\beta_{0}=0.817$. $\beta$ depends on the reduced mass of the sphere $\tilde{m}$, i.e. the ratio of the mass of the sphere $m_{S}$ to the mass of the cantilever $m_{C}$, and on the reduced gyration radius of the sphere $\tilde{r}$, proportional to the ratio of the radius $R$ of the sphere to the length $L$ of the cantilever. For small tips, $\tilde{m}$ and $\tilde{r}$ are negligibly small, and $\beta=\beta_{0}$, therefore $K^{t h}=K_{0}^{t h}$. In our case, since $L=350 \mu \mathrm{m}, m_{C}=2.65 \times 10^{3} \mathrm{ng}, m_{S}=1.05 \times 10^{3}$ ng, we had $\tilde{m}=0.4$ and $\tilde{r}=0.03$, therefore corrections were needed. 


\subsection{Production of nanotopographical and reference CPs}

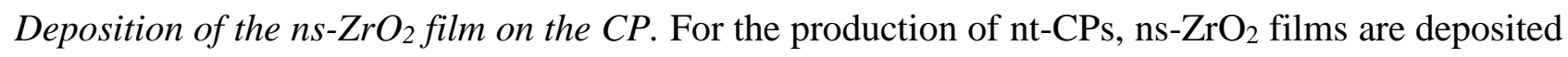
on the colloidal probes exploiting an SCBD apparatus equipped with a Pulsed Microplasma Cluster Source $^{79,80}$ (Figure 2). Partially oxidised zirconia clusters are produced within the PMCS and then extracted into the vacuum through a nozzle to form a seeded supersonic beam. Clusters are collected directly on the CPs intercepting the beam, in the deposition chamber. Upon landing on the probe surface, which is locally flat due to the large radius, clusters form a nanostructured, highly porous, high-specific area, biocompatible $\mathrm{ns}^{-} \mathrm{ZrO}_{2}$ film ${ }^{44,58,59,81,82}$. The oxidation of the nanostructured film further proceeds upon exposure to air, up to an almost complete stoichiometry, although rich of local defects. The crystalline phase is cubic at room temperature ${ }^{62}$.

The root mean square (rms) roughness $r_{q}$ of the deposited film, defined as the standard deviation of surface height values, evolves with the film thickness $h$, according to the power law ${ }^{59,60}$ $r_{q} \sim h^{b}$, where $b=0.35$ approximately (details about the evolution of the roughness-thickness relation and on the mechanical stability of the nanostructured thin film can be found in the Supporting Information, Figures S1,2) $)^{60,62}$. Therefore, by controlling the thickness of the film deposited using a quartz microbalance placed inside the deposition chamber, it is possible to produce nanotopographical CPs with very high reproducibility. The typical thickness of the ns- $\mathrm{ZrO}_{2}$ films deposited on CPs was in the 70-250 nm range, corresponding to roughness values in the range $13-20 \mathrm{~nm}$. 


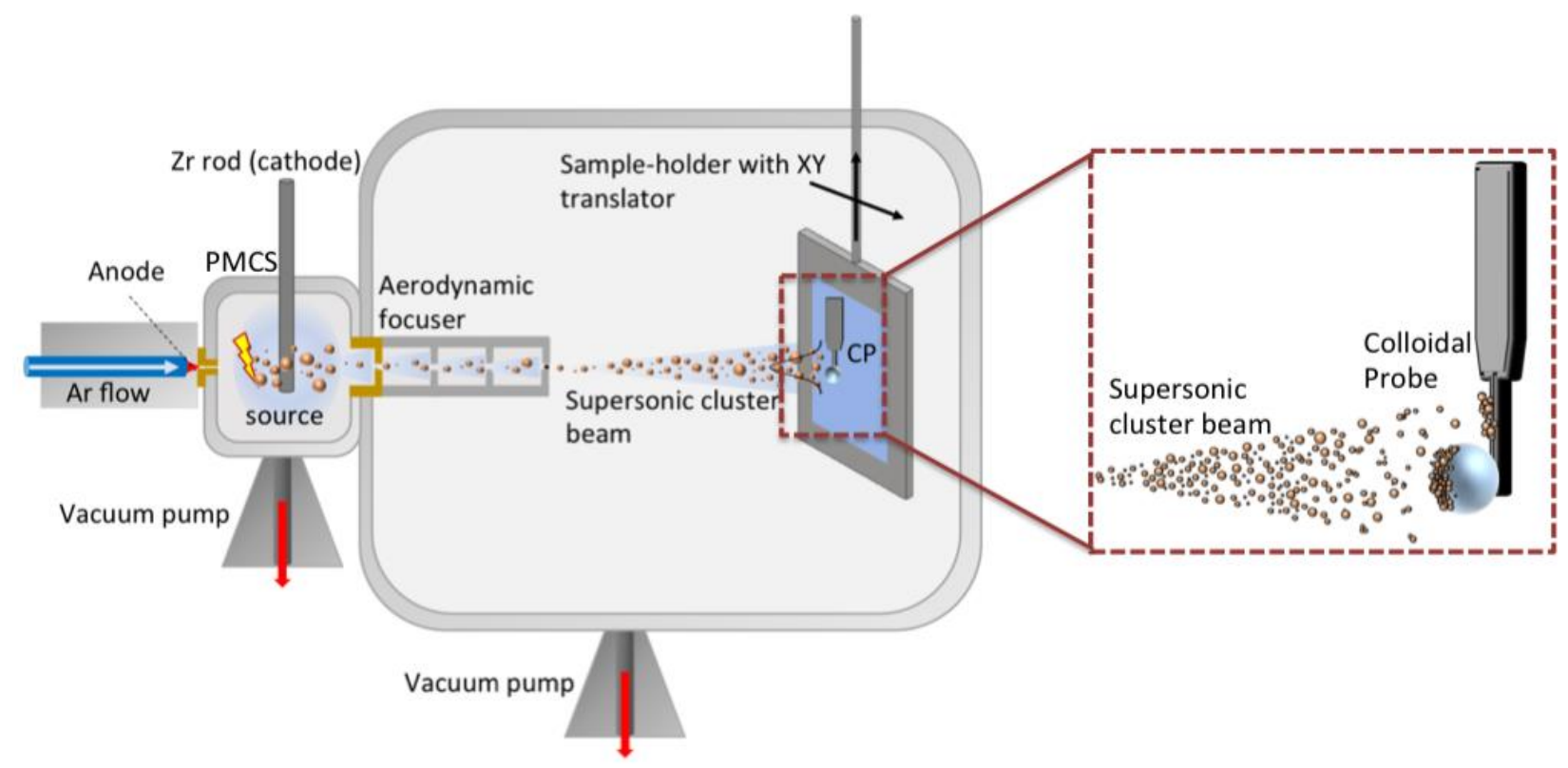

Figure 2. A schematic representation of the SCBD apparatus for the production of $n t-C P s . T h e \mathrm{Zr}$ rod is sputtered by a plasma discharge, triggered by the introduction of argon (Ar) through a pulsed valve into the source cavity and the application of a high voltage between the Zr rod and the anode. The ablated species condense into clusters and the resulting gas-clusters mixture is extracted through a nozzle and an aerodynamic focuser into a high vacuum chamber; during the process, the carrier gas-clusters mixture undergoes a supersonic expansion. The cluster beam impinges on the $\mathrm{CP}$, where a thin, nanostructured $\mathrm{ZrO}_{2}$ film is formed.

Deposition of smooth $\mathrm{ZrO}_{2}$ films on the CP. Thin, compact and very smooth coatings of $\mathrm{ZrO}_{2}$ (flat$\mathrm{ZrO}_{2}$ ) with rms roughness below $1 \mathrm{~nm}$ were deposited by ion sputtering on the CPs, in order to produce reference interacting surfaces, without any nanotopographical cues. To this purpose, a Kaufman ion gun (Cyberis 40-f) was used to sputter a $\mathrm{Zr}$ target. The produced coating is partially oxidised in the deposition chamber; oxidation further proceeds upon exposure to ambient air.

Production of Poly-L-lysine -coated CPs. Also for reference purposes, CPs were coated with polyL-lysine (PLL). PLL is a poly-amino acid routinely used to facilitate protein absorption and the attachment of cells to solid surfaces in biological applications, including our previous experiments with PC12 cells ${ }^{44,64}$. For the PLL coating, the probes were incubated with a $0.1 \%$ (w/v) PLL solution (Sigma-Aldrich) at room temperature for $30 \mathrm{~min}$, and washed thoroughly afterwards with milliQ water several times before the measurements. 


\subsection{Force spectroscopy experiments and data analysis}

Force spectroscopy. The force spectroscopy experiments were performed using a Bioscope Catalyst AFM (Bruker). During the AFM measurements, the temperature of the medium was maintained at $37^{\circ} \mathrm{C}$ using a perfusion stage incubator and a temperature controller (Lakeshore 3301, Ohio, USA). The colloidal probes were incubated with the cell culture medium for $>30$ min at $37^{\circ} \mathrm{C}$ before the actual measurements.

The deflection sensitivity was calibrated in situ and non-invasively before every experiment by using the previously characterised spring constant as a reference, according to the SNAP procedure described in Ref. ${ }^{41}$ The standard approach, i.e. pressing the probe on a stiff surface and measuring the inverse of the slope of the force curve in the contact region, could likely cause contamination of the nt-CP surface and damage of the nanotopographical asperities. Moreover, friction-dependent issues can influence the accuracy of the determination of the deflection sensitivity by the standard contact method, when using large CPs ${ }^{83}$.

Sets of raw deflection versus approaching distance curves were acquired at locations on the cells body selected by means of the optical microscope. The raw curves where converted into force versus distance curves (shortly force curves, FCs), rescaling the deflection axis by multiplication by the deflection sensitivity and the cantilever spring constant, and summing the cantilever deflection to the Z-piezo displacement axis ${ }^{84}$ (see Figure 3a). FCs containing 8192 points each were recorded on cells, with ramp length $l=8 \mu \mathrm{m}$, maximum load $F_{\max }=1 \mathrm{nN}$ and retraction speed at $v_{r}=16$ $\mu \mathrm{m} / \mathrm{s}$. The pulling speed was kept relatively low to reduce hydrodynamics effects ${ }^{85}$.

To measure the early steps of cellular adhesion, we selected five contact times $(c t s): 0,20$, 60, 120, 240 s, accordingly. During the contact time, the Z-piezo position was kept constant using the $\mathrm{Z}$ closed-loop feedback mode. Long contact times require a very stable system; this condition is obtained by means of both an active anti-vibration base (DVIA-T45, Daeil Systems) and an acoustic enclosure for the AFM (Schaefer Italy), by controlling the environmental temperature in the laboratory, and by allowing for a long equilibration time $(30 \mathrm{~min})$ before starting the experiments. Figure S3 shows that the drift along the vertical direction during contact of the CP with the sample is very small (max. $20 \mathrm{~nm}$ in $240 \mathrm{~s}$ ), and determines a negligible variation of the applied force.

To reduce the stress on the cells and not to alter their adhesive behaviour, a maximum applied load of $1 \mathrm{nN}$, corresponding to a pressure of the order of $10 \mathrm{~Pa}$, was set during the 
acquisition of the FCs. For the same reason, the number of FCs collected per cell was limited (not only because of the very long acquisition time of each curve).

Data analysis. Data processing of the sets of curves was carried out in Matlab (Mathworks) environment using custom routines.

The values of several parameters were calculated for the analysis of the cell-probe detachment mechanisms (Figures 3a,b). In particular, we inferred the maximum cell-probe adhesion force $F_{a}$ and the work of detachment $W$ required to separate the nt-CP from the cell. $W$ is calculated as the area below the force versus distance curve. The maximum detachment force $F_{a}$ depends on different properties of the cell, such as overall rigidity, cortex tension, cell shape, single binding strength and spacing. Compared to $F_{a}, W$ provides a more complete, integrated information about the cell adhesion, related to the numbers, lengths and strengths of all bonds formed between the nt$\mathrm{CP}$ and the cell. Moreover, we extracted the number $N_{j, t}$ and strength $F_{j, t}$ of the single unbinding events of every FC measured (for both, jumps $j$, and tethers $t$ ). The unbinding events must be identified in the retraction section of the $\mathrm{FCs}^{86,87}$ : we exploited the numerical derivative of the curves with respect to the tip-sample distance ${ }^{88}$ (Figure $3 b$ ) to detect the location of the events.

Statistics and error analysis. Mean values $\psi_{\text {mean }}$ and associated errors $\sigma_{\text {mean }}$ (based on the standard deviation of the mean) were calculated for each observable $\psi\left(F_{a}, W, N_{j, t, \ldots}\right)$, as described in detail in the Supporting Information. These values and errors represent a population of cells in a given condition. To this purpose, first mean values and errors have been calculated for the single cells tested, then these values have been averaged and the resulting error calculated.

For each nt-CP used, 10 cells were measured (with 3 FCs for each cell). This resulted in 30 FCs per time point for each probe, and 50 cells and 150 FCs investigated for each probe in total. 

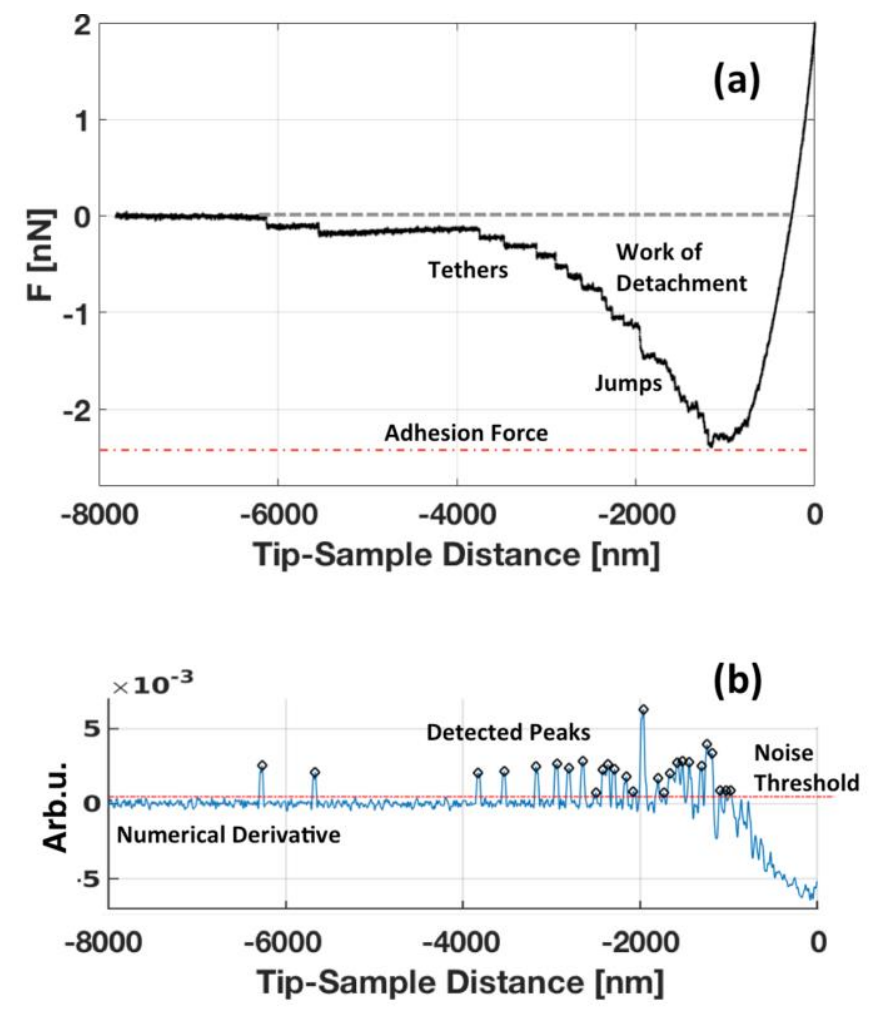

Figure 3. (a) The retraction part of a representative $F C$, with the two different possible unbinding events, jumps and tethers, total adhesion force and work of detachment shown. (b) Numerical derivative of the FC used to identify and locate the unbinding events.

\subsection{Cell Culture and preparation for the force spectroscopy experiments}

As cellular model we used neuron-like PC12 cells (i.e., in particular the PC12-Adh clone, ATCC Catalogue No. CRL-1721.1TM). These cells interact with ns- $\mathrm{ZrO}_{2}$ films, reacting with mechanotransductive responses to the provided nanotopographical stimuli ${ }^{44,58,64}$.

For routine cell culture (subculturing every 2-3 days), the cells were kept in an incubator (Galaxy S, RS Biotech) at $37^{\circ} \mathrm{C}$ and $5 \% \mathrm{CO}_{2}$, in RPMI-1640 medium supplemented with $10 \%$ horse serum, 5\% fetal bovine serum, $2 \mathrm{mM}$ L-Glutamine, $10 \mathrm{mM}$ HEPES, 100 units/mL penicillin, $1 \mathrm{mM}$ pyruvic acid, and $100 \mu \mathrm{g} / \mathrm{mL}$ streptomycin (all reagents from Sigma Aldrich, if not stated otherwise).

For the force spectroscopy experiments, the cells were detached from the cell culture flasks with trypsin/EDTA solution, counted with an improved Neubauer chamber, and plated in low 
concentration of 4.000 cells $/ \mathrm{cm}^{2}$ (to guarantee the presence of single separated cells) on $\emptyset 40 \mathrm{~mm}$ glass-bottom dishes for cell culture (Willco Wells) the day before the experiment. Phenol-red free solutions were used for the experiments, since this molecule was found to be harmful for the AFM tip holder. Directly before the cell plating, the $\emptyset 40 \mathrm{~mm}$ glass-bottom dishes were coated with PLL (incubation with a $0.1 \%$ PLL solution for $30 \mathrm{~min}$ at RT, followed by several washing steps with PBS) and sterilised with UV light for $10 \mathrm{~min}$. After cell plating, the cells were kept overnight in the incubator to guarantee good cell attachment before the force spectroscopy experiments.

For the integrin activation, the cells were pre-incubated with manganese chloride $\left(\mathrm{MnCl}_{2}\right)$ at a concentration of $1 \mathrm{mM}$ for $>10 \mathrm{~min}$ before the measurements (the treatment has been labelled $\mathrm{Mn}^{2+}$ in figures). In case of inhibition of the $\beta 1$ integrin activity, the cells were pre-incubated with the inhibitory $4 \mathrm{~b} 4$ antibody (Beckman Coulter) at a concentration of $5 \mu \mathrm{g} / \mathrm{mL}$ for $>15$ min before the measurements (the treatment has been labelled $4 \mathrm{~b} 4$ in the figures).

\section{RESULTS AND DISCUSSION}

\subsection{Characterisation of the nanotopographical colloidal probes}

Figure 4 shows representative AFM images of a clean borosilicate glass sphere before (Figure $4 \mathrm{a}$ ) and of the same sphere after deposition of the ns- $\mathrm{ZrO}_{2}$ film (Figure $4 \mathrm{~b}$ ) used for the production of a nt-CP.

$\mathrm{Ns}-\mathrm{ZrO}_{2}$ grows on the curved $\mathrm{CP}$ surface, as it does on conventional flat smooth substrates (see Supporting Information for details).

The structure and morphology of these cluster-assembled films result from the random stacking and aggregation of impinging nanometer-sized building blocks (the $\mathrm{ZrO}_{2}$ clusters) into larger and larger units. The surface profiles of nanostructured zirconia films are characterised by peaks and valleys (see Figure 4c), defining a complex random pattern of nanoscale features, whose dimensions and spatial distribution resemble those found in natural ECM topographies ${ }^{5,6}$. The specific surface area, the rms roughness, the average lateral dimensions of the largest morphological features (the correlation length $\xi$ ), as well as the interfacial porosity of the films typically increase with film thickness ${ }^{59,60,89}$. The interfacial open pores, delimited and defined by the surface asperities $^{44}$, can accommodate proteins (including fibronectin) and nutrients ${ }^{31,89-92}$; asperities evolve in height, area, and surface charge density ${ }^{81}$. 
bioRxiv preprint doi: https://doi.org/10.1101/2020.01.02.892919; this version posted March 5, 2020. The copyright holder for this preprint (which was not certified by peer review) is the author/funder, who has granted bioRxiv a license to display the preprint in perpetuity. It is made available under aCC-BY-ND 4.0 International license.

In this work, we concentrated our attention on nt-CPs with rms roughness of the ns- $\mathrm{ZrO}_{2}$ film $r_{q}=15 \mathrm{~nm}$. This particular value of $r_{q}$ was chosen because we recently demonstrated that it induces in PC12 cells mechanotransductive modulations at the level of integrin adhesion complexes and cytoskeleton (Figure 1b), as well as differentiative events, such as neuritogenesis, and a vast change in the cellular program ${ }^{44,58,64}$.

(a)

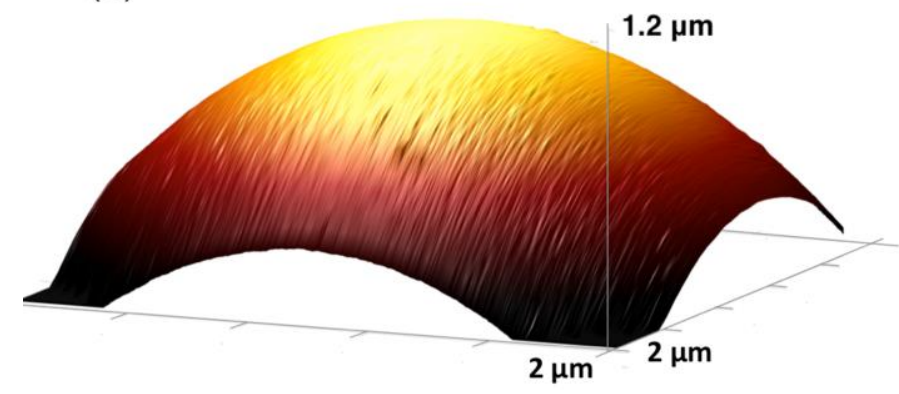

(b)
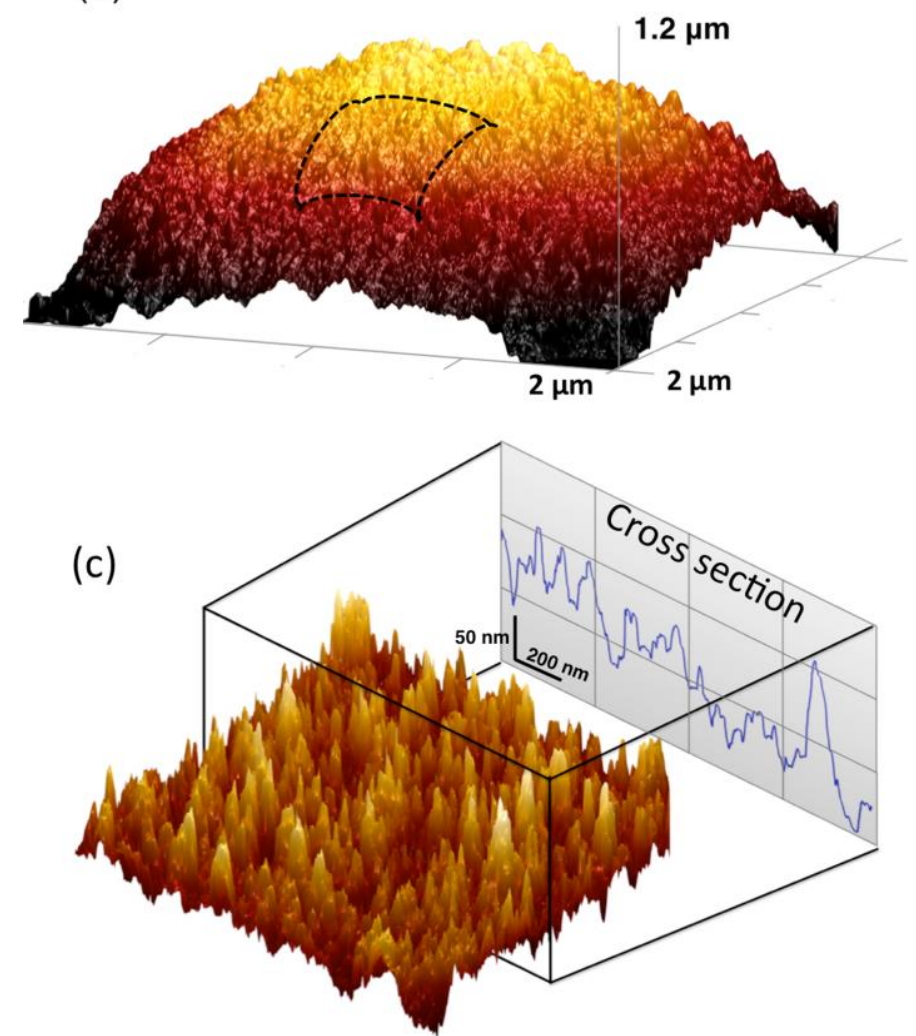

Figure 4. The surface morphology characterised by AFM of a borosilicate glass sphere. (a) Before, and (b) after the deposition of $n s-\mathrm{ZrO}_{2}\left(r_{q}=15 \mathrm{~nm}\right)$. (c) A higher resolution AFM image (the 
bioRxiv preprint doi: https://doi.org/10.1101/2020.01.02.892919; this version posted March 5, 2020. The copyright holder for this preprint (which was not certified by peer review) is the author/funder, who has granted bioRxiv a license to display the preprint in perpetuity. It is made available under aCC-BY-ND 4.0 International license.

baseline curvature was removed) from the nt-CP shown in Figure 4b; the cross section highlights distinct peaks and valleys at the nanoscale.

\subsection{Cell adhesion dynamics at nanotopographical interfaces}

To investigate in which way nanotopographical features influence the characteristics of cellular adhesion processes, we performed adhesion force spectroscopy on PC12 cells with four CPs, possessing different types of functionalisation:

1) ns- $\mathrm{ZrO}_{2}$-coated $\mathrm{CP}$, produced by SCBD, with $r_{q}=15 \mathrm{~nm}$ (surface: $\mathrm{ns}^{-} \mathrm{ZrO}_{2}$ ).

2) flat $\mathrm{ZrO}_{2}$-coated $\mathrm{CP}$, produced by ion gun sputtering, without nanotopographical features (surface: flat- $\mathrm{ZrO}_{2}$ ).

3) borosilicate glass CP (surface: glass).

4) poly-L-lysine -coated CP (surface: PLL).

PLL coatings are routinely used to facilitate protein absorption and cell adhesion to solid surfaces (in particular glass) in biological applications (by providing positively charged sites favouring electrostatic interactions), which represents also the canonical substrate condition for PC12 cell experimentation. In our previous work, we found that the PC12 cells formed FA and stress fibres on the PLL-coated glass and flat zirconia substrates, whereas on the $\mathrm{ns}^{-\mathrm{ZrO}_{2}}\left(r_{q}=\right.$ $15 \mathrm{~nm})$ substrate the adhesion sites remained at focal complex dimensions and the stress fibre formation was reduced $^{44}$ (Figure 1a). CPs number 2, 3 and 4 were therefore used as controls.

The dependence on the contact time $c t$ of the measured parameters (maximum adhesion force, work of detachment, number of unbinding events for jumps and tethers) is discussed in the next paragraphs. 

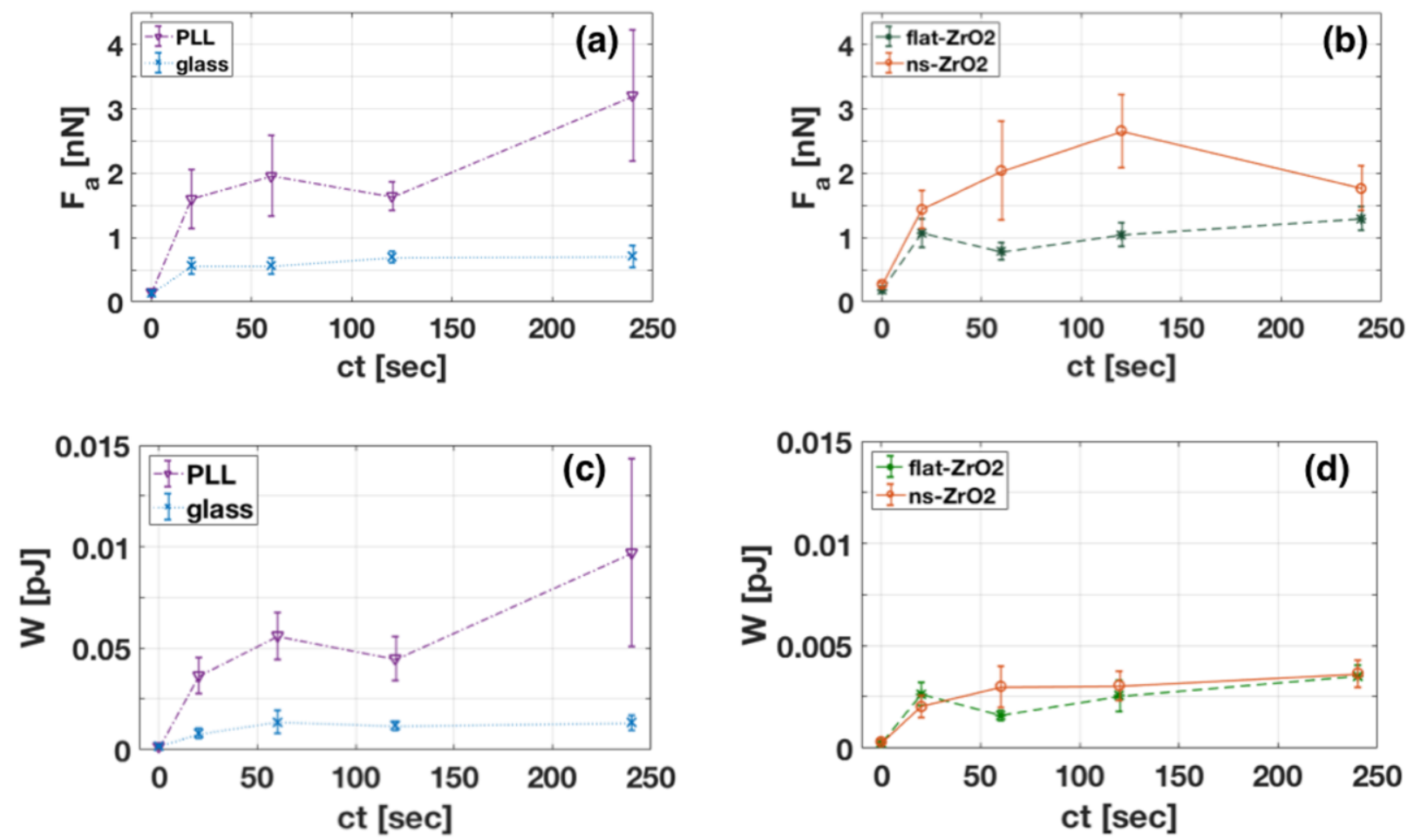

Figure 5. Dependence of the maximum adhesion force on the contact time for the four investigated surfaces. (a) On the left, the colloidal glass probes, untreated (glass, blue line) or with PLL functionalisation (PLL, violet line). (b) On the right, the two colloidal probes decorated with zirconia films, flat (flat-ZrO $=15 \mathrm{~nm}\left(\mathrm{~ns}-\mathrm{ZrO}_{2}\right.$, orange line $)$. (c, d) Dependence of the work $W$ on the contact time for the same surfaces as in $(a, b)$.

Maximum adhesion force $F_{a}$. Figures 5a,b show that the cells are capable to create stronger adhesion on all functionalised surfaces, compared to the untreated glass. Nevertheless, the extent of these differences compared to the reference glass surface, and the temporal evolution of the adhesion, are different on each surface.

On glass and flat zirconia, $F_{a}$ rapidly reaches a plateau, although on flat- $\mathrm{ZrO}_{2}$ the final value is higher. On ns- $\mathrm{ZrO}_{2}$ and PLL, $F_{a}$ follows a similar growing trend in the first $60 \mathrm{~s}$, reaching much higher values than flat- $\mathrm{ZrO}_{2}$. PLL is the only surface where adhesion increases during the whole time interval, achieving its maximum values at $240 \mathrm{~s}$ (with the highest value of all the conditions). On the nanotopographical surface, the $F_{a}$ maximum is reached at $120 \mathrm{~s}$, then adhesion decreases to a value similar to that on flat- $\mathrm{ZrO}_{2}$.

Work of Detachment $W$. The temporal evolution of the work of detachment $W$ provides additional information about the level of complexity and the maturation of the cellular adhesion (Figure $5 \mathrm{c}, \mathrm{d}$ ). While the trends of $W$ for glass and PLL-coated glass are similar to those of $F_{a}$, this 
is not the case for zirconia surfaces; in this case, while the evolution of $F_{a}$ was different for the two surfaces, the evolution of $W$ is similar. Moreover, the measured work for both flat and $\mathrm{ns}-\mathrm{ZrO}_{2}$ never reaches the value of the PLL-coated glass. Since the work is a force times a distance, a different trend of $\mathrm{W}$ compared to $F_{a}$ can be attributed to either different numbers of bonds (detected as unbinding events), or to different bond lengths, or both.

Mean number of unbinding events $N_{j}, N_{t}$. The mean number of detected unbinding events for cells interacting with different surfaces (Figure 6) revealed distinct differences in the temporal adhesion dynamics between PLL, ns- $\mathrm{ZrO}_{2}$ and flat- $\mathrm{ZrO}_{2}$, in particular with respect to the jump events $N_{j}$, which we discuss first (Figure 6a,b).

The jump events in force curves are predominantly attributed to receptors in the membrane that are anchored to the cytoskeleton (as e.g. integrins in molecular clutches via talin) $)^{48,51-54,93-95}$.

PLL-coated glass (Figure 6a) and $\mathrm{ns}^{-\mathrm{ZrO}_{2}}$ (Figure 6b) show a similar progression of the $N_{j}$ in the first $20 \mathrm{~s}$ (with both reaching 10 events), after which they develop differently. The $N_{j}$ of PLL reaches a maximum at $60 \mathrm{~s}$, and also later on the cells created significantly more jump adhesion spots on the PLL compared to flat and ns- $\mathrm{ZrO}_{2}$.

In the nanotopographical surface condition, $N_{j}$ decreases strongly $(-53 \%)$ from $20 \mathrm{~s}$ to $60 \mathrm{~s}$. Intriguingly, this drop is a recurrent and specific phenomenon that appears systematically for all investigated cells interacting with the nanotopographical surface. In the flat- $\mathrm{ZrO}_{2}$ condition, there is instead a progressive rise of $N_{j}$ in the first 120 s (reaching 8 events and being always higher than glass).

The evolution of the number of tethers $N_{t}$ (Figure $\left.6 \mathrm{c}, \mathrm{d}\right)$ instead is more similar for all four conditions.

The nature of the tethers has been poorly investigated, but they are usually associated to receptors that are not anchored to the internal actin cortex, which results in membrane extrusion from the cell reservoir ${ }^{93-95}$. Another hypothesis is that tether events could, at least partially, be related to the unfolding of glycocalyx sugar chains ${ }^{96}$. It has been demonstrated that the tethers do not respond as a catch bond ${ }^{52}$, and also in our experimental set-up they seem to participate in a negligible manner to the maturation of the adhesion (with a generally low contribution to $F_{a}$, see Supporting Information, Figure S4), showing only minor divergent reactions towards the different surface conditions.

In the following, we will concentrate our attention mainly on the $N_{j}$ parameter. 

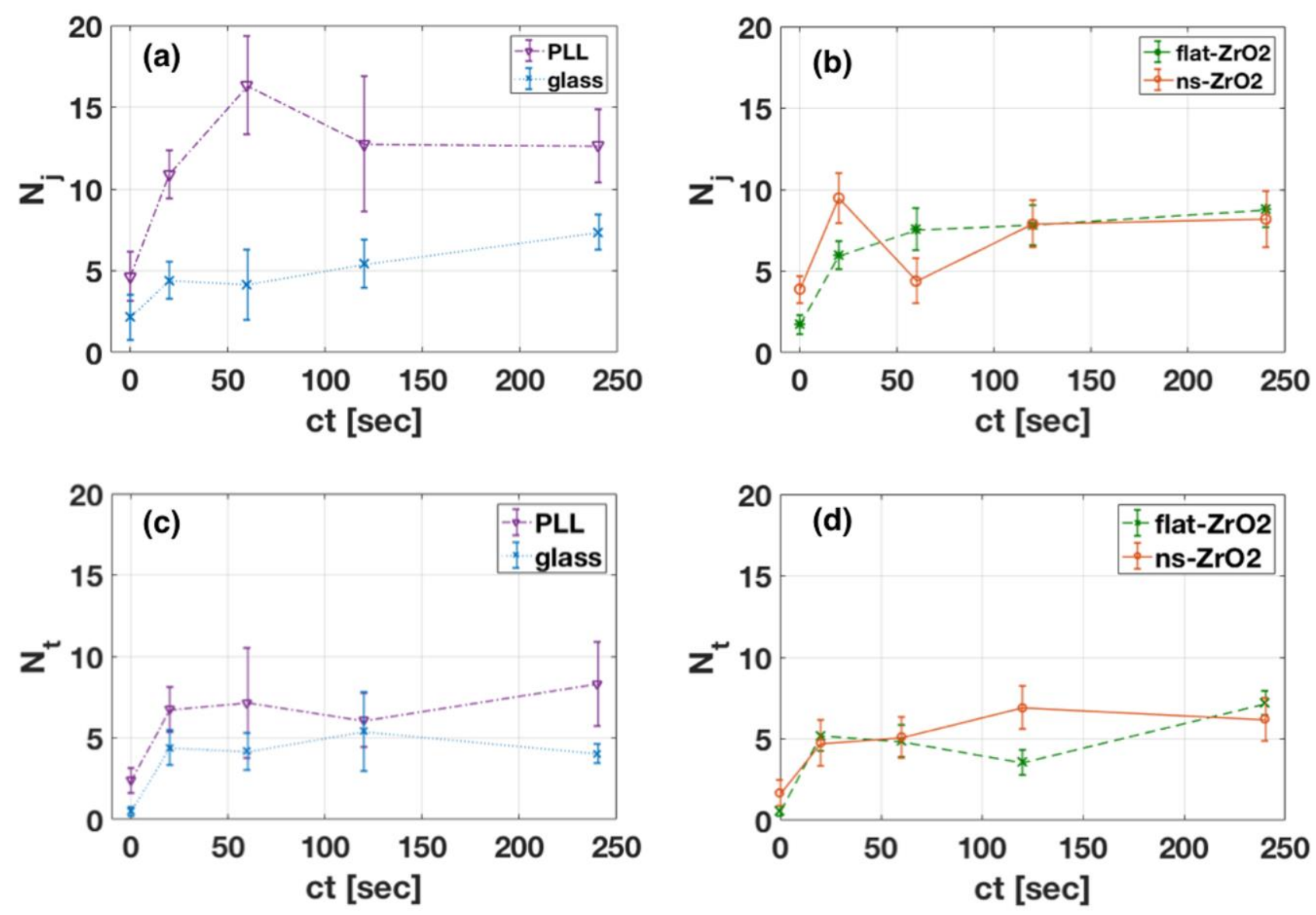

Figure 6. Dependence of the mean number of unbinding events on the contact time. (a,b) Mean number of jumps events $N_{j}$ (see Figure 2 for details) for (a) the colloidal glass probes, untreated (glass-CP, blue line) or with PLL functionalisation (PLL, violet line), and for (b) the two colloidal probes with zirconia films, flat (flat-ZrO $\mathrm{Z}_{2}$, green line) or with nanotopographical features with a roughness of $r_{q}=15 \mathrm{~nm}$ (ns- $\mathrm{ZrO}_{2}$, orange line). (c,d) The same as in $(a, b)$ for the mean number of tether events $N_{t}$ (see Figure 2 for details).

The interaction time window between 20 and 120 s seems to be the most interesting for the dynamics of the adhesion spots on different surfaces, in particular when looking at the combined evolution of the different parameters (e.g., $F_{a}$ and $N_{j}$ ).

PLL and ns- $\mathrm{ZrO}_{2}$ have a comparable development of $F_{a}$ from 20 to $60 \mathrm{~s}$, whereas the $N_{j}$ evolve in a converse manner, i.e. it increases markedly for PLL, and decreases for the nanotopographical surface (Figure 6a,b). Glass and flat- $\mathrm{ZrO}_{2}$ instead show more moderate alterations.

In order to better investigate these dynamical phenomena, we have calculated the mean adhesion force per jump $\left\langle F_{j}\right\rangle$ (see Supporting Information for details, Figure S4). The result is 
shown in Figure 7. An interesting outcome specific for the $\mathrm{ns}-\mathrm{ZrO}_{2}$ surface is visible. While the average force per single jump (between 20 - $120 \mathrm{~s}$ ) is similar for all the surfaces without nanotopographical features, i.e. glass, PLL, and flat- $\mathrm{ZrO}_{2}$, a sudden 3.3-fold increase of the single jump strength (from $20 \mathrm{~s}$ to $60 \mathrm{~s}$ ) is evident for $\mathrm{ns}-\mathrm{ZrO}_{2}$ (for flat $-\mathrm{ZrO}_{2}$ it actually drops by $50 \%$ in the same time frame). At regime, after $240 \mathrm{~s}$, the force $\left\langle F_{j}\right\rangle$ converges down to the value of the other surfaces, nevertheless it remains significantly higher compared to glass and flat- $\mathrm{ZrO}_{2}$ for most of the time.

Interestingly, these divergent dynamics happen in the critical time window for molecular clutch reinforcement, the initiation of integrin clustering and nascent adhesion growth ${ }^{52,97}$.

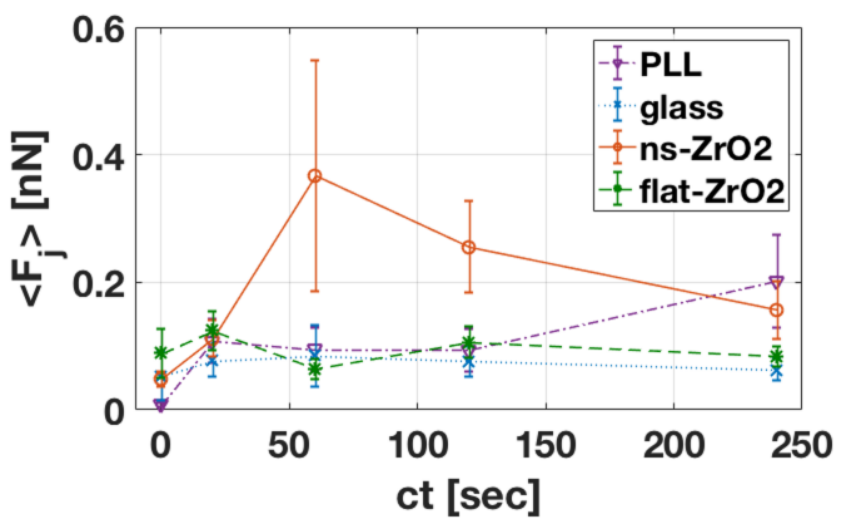

Figure 7. Evolution of the mean jump force versus the contact time for the different surfaces (glass: blue line; PLL: violet line; flat- $\mathrm{ZrO}_{2}$, green line; $\mathrm{ns}_{\mathrm{S}} \mathrm{ZrO} \mathrm{O}_{2}$, orange line).

\subsection{Adhesion dynamics to the nanotopographical probe are influenced by the availability of activated integrin and depend, at least partially, on $\beta 1$ integrin}

Due to our previous data on the effects of the nanotopography on the configuration of integrin adhesion sites ${ }^{44}$ and the interesting chronology of the jump adhesion events and force development observed for the $\mathrm{ns}-\mathrm{ZrO}_{2}$ surface, we tested in which way these dynamics towards the nanotopography depend on the integrin activity.

In a first step, we examined how an excess of integrin activation would affect the early adhesion dynamics towards the nanotopographical surface. To this purpose, we activated the integrins with $\mathrm{Mn}^{2+}$. This treatment kept the $N_{j}$ from dropping after $60 \mathrm{~s}$, as it was observed on the ns- $\mathrm{ZrO}_{2}$ surface without $\mathrm{Mn}^{2+}$ activation (Figure $8 \mathrm{a}$ ).

This impact of the abundant availability of activated integrins might be explained by two effects (or a combination of both). In nascent adhesions, $\mathrm{Mn}^{2+}$-induced integrin activation is known 
to increase the density within integrin clusters $^{98}$; moreover, unligated activated integrins could favour the bridging between separated, but adjacent adhesion sites ${ }^{99}$. In any case, the force loading can be distributed over more active integrins, confirmed by the decrease of mean force per jump event at $60 \mathrm{~s}$ due to the $\mathrm{Mn}^{2+}$ treatment (Figure 8b), which stabilises the adhesion sites.
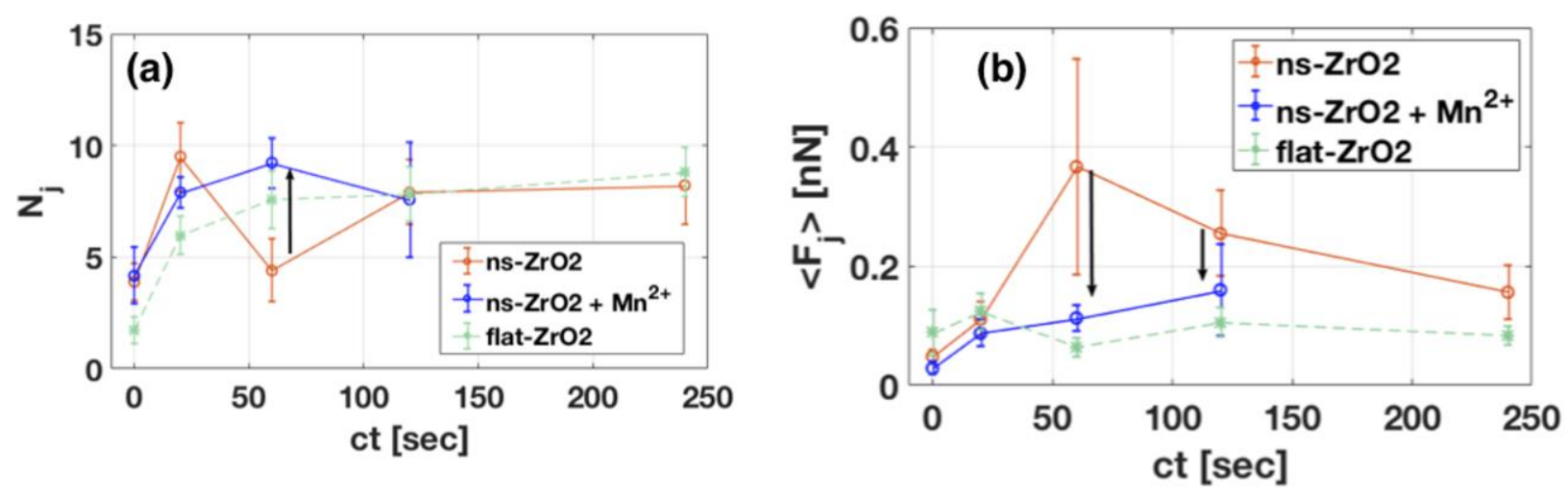

Figure 8. (a) Mean number of jumps $\mathrm{N}_{j}$ detected on $n s-\mathrm{ZrO}_{2}$ surface before (orange) and after (blue) $\mathrm{Mn}^{2+}$ treatment versus the contact time. (b) Mean jump force $\left\langle F_{j}>\right.$ measured on $n s-\mathrm{ZrO}_{2}$ before (orange) and after (blue) $\mathrm{Mn}^{2+}$ treatment versus the contact time. The flat-ZrO $\mathrm{Z}_{2}$ cases (green, reproduced from Figure 7) are also shown for sake of comparison. The black arrows highlight the effect of the $\mathrm{Mn}^{2+}$ treatment on both $\mathrm{N}_{j}$ and $\left\langle F_{j}\right\rangle$ in the $n s-\mathrm{ZrO}_{2}$ condition.

Furthermore, we treated the cells with an allosteric inhibitory antibody against $\beta 1$ integrin (4b4), to see how this would impact on $N_{j}$ at later stages, when integrin clustering strongly manifests (120 and $240 \mathrm{~s}$ ). As shown in Figure 9, in the presence of the $4 \mathrm{~b} 4, \mathrm{~N}_{j}$ decreased by $42 \%$ at $120 \mathrm{~s}$, and by $60 \%$ at $240 \mathrm{~s}$. Since $\beta 1$ integrin represents the most common, but not the only, $\beta$ integrin subunit, this result demonstrates that the recorded jump interaction events depend, at least partially, on the activation of $\beta 1$ integrin subunit-containing integrin receptors. This outcome is in line with the involvement of the $(\beta 1)$ integrin activation and signalling in the nanotopographysensitive modulations in PC12 cell mechanotransduction and differentiative behaviour (in particular neuritogenesis) we have previously reported ${ }^{44,64}$.

Altogether, these results indicate that the availability of activated integrins seems to be an influential regulatory factor for spatial sensing of adhesion sites at the nanoscale. 


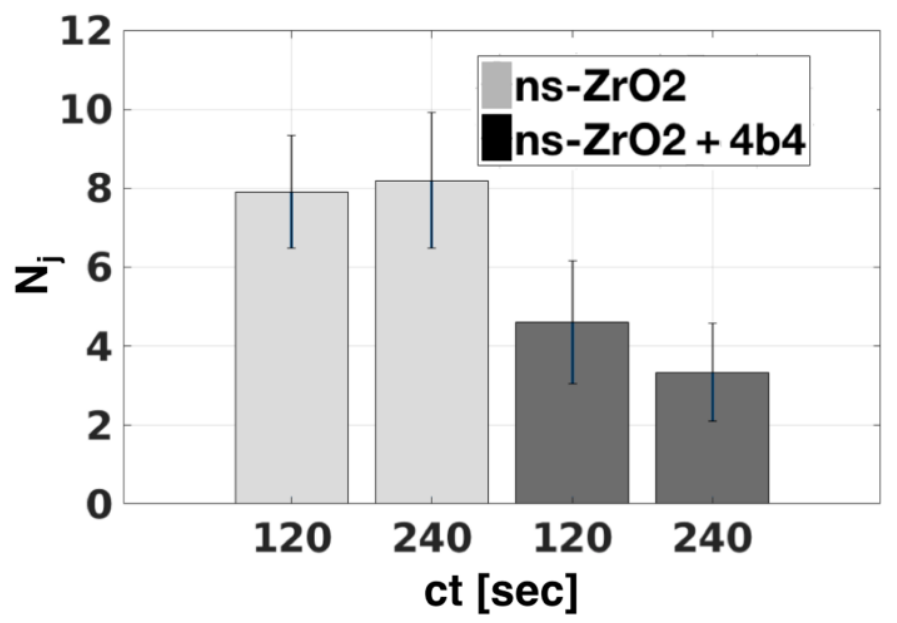

Figure 9. Mean number of jumps $N_{j}$ in the $n s-Z r O_{2}$ condition before (grey) and after (dark grey) the $4 \mathrm{~b} 4$ antibody treatment $(5 \mu \mathrm{g} / \mathrm{mL})$, for $c t=120 \mathrm{~s}$ and $c t=240 \mathrm{~s}$.

\subsection{Evolution of jump force distribution over time.}

For a better understanding of the dynamics of the adhesion force development on the different surfaces, we analysed in greater detail the distribution of the measured strengths of the single jumps at different contact time $c t$.

\begin{tabular}{cc}
\hline \hline Surfaces & Most probable jump force at $\mathbf{c t}=\mathbf{0}(\mathbf{p N})$ \\
\hline flat-ZrO 2 & $42 \pm 15$ \\
ns- $\mathrm{ZrO}_{2}$ & $36 \pm 13$ \\
glass & $21 \pm 10$ \\
PLL & $19 \pm 17$ \\
\hline
\end{tabular}

Table 1. Most probable jump force at $c t=0$ s. 

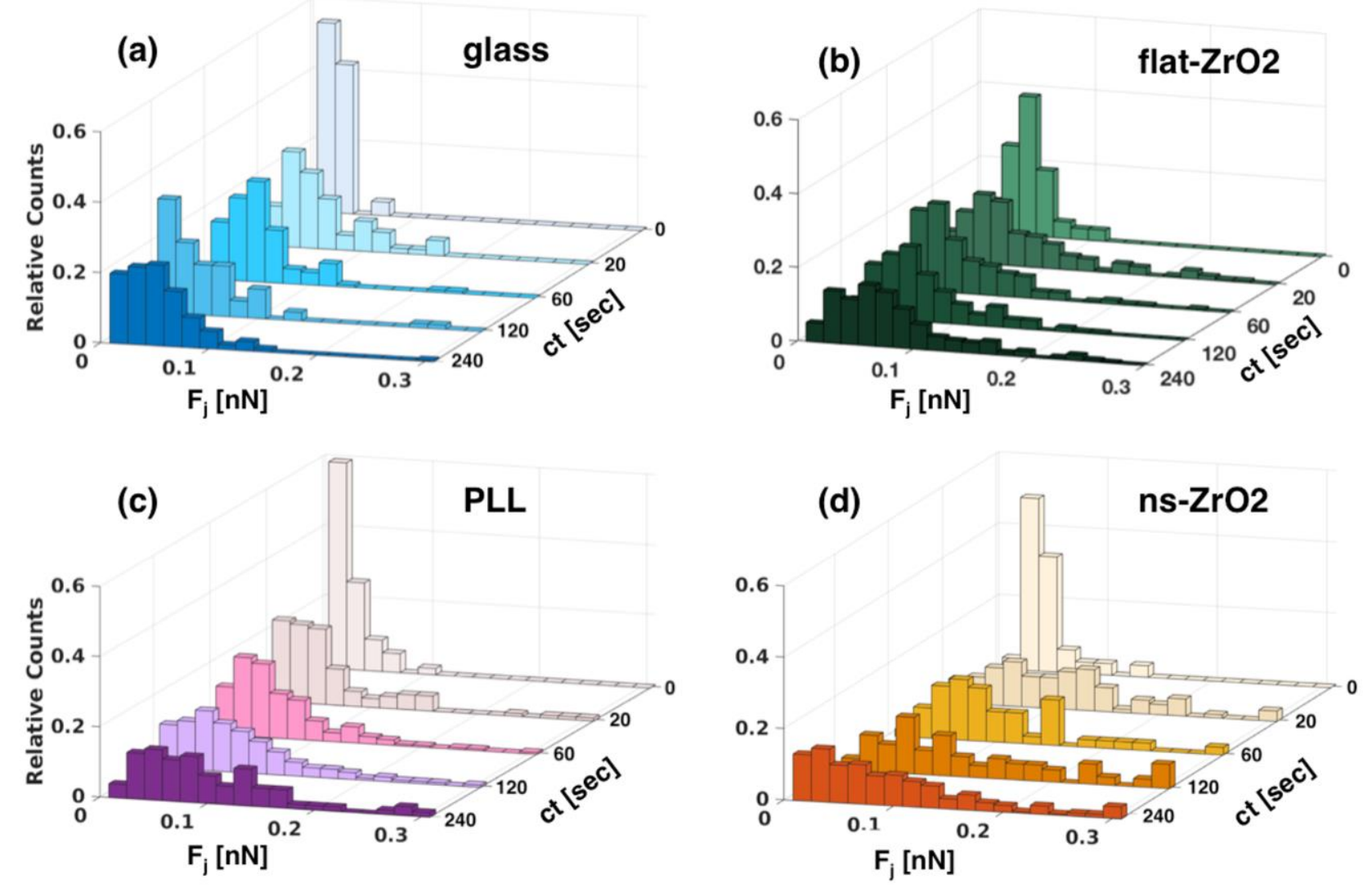

Figure 10. Evolution of the jump force distribution with contact time for (a) glass (blue bars), (b) PLL (violet bars), (c) flat- $\mathrm{ZrO}_{2}$ (green bars) and (d) $n s-\mathrm{ZrO}_{2}$ (orange bars). The relative counts are the abundances of unbinding events (in each bar) normalised to total number of unbinding events

At $c t=0 \mathrm{~s}$, the distributions of jump forces are similar for all surfaces, with a leading peak detected around $40 \mathrm{pN}$ for zirconia surfaces and $20 \mathrm{pN}$ for glass and PLL (see Table 1). The immediate appearance of a force peak in this range is consistent with the recently shown very fast integrin adhesion response (in that case for $\alpha 5 \beta 1$ integrin/fibronectin binding) ${ }^{50}$. The range is also compatible with the reported peak tension of single integrin-ligand bonds during initial adhesion $^{51,100-104}$ and furthermore, it coincides with the force thresholds for the extension of the talin rod, vinculin recruitment and molecular clutch reinforcement ${ }^{105}$.

With the increase of $c t$, we observed that on glass and PLL the mean jump force remains almost constant, with the appearance of a minor peak at higher forces around $120 \mathrm{pN}$ (Figure $10 \mathrm{a}, \mathrm{c}$ ). The distribution of flat $-\mathrm{ZrO}_{2}$ (Figure 10b) is similar, although the peaks are broader and there are more counts at higher forces. 
On ns- $\mathrm{ZrO}_{2}$ (Figure 10d) the distribution of forces, already after $20 \mathrm{~s}$, shifts towards higher forces, even above $200 \mathrm{pN}$. High force bonds $(>100 \mathrm{pN})$ appear almost with the same frequency $(\sim 45 \%)$ as the weaker ones $(<100 \mathrm{pN})$ at every time point ( 0 s excluded).

Regarding the adhesion force $F_{a}$ (Figure $5 \mathrm{~b}$ ), this increased strength of the single jumps actually compensates for the lower number of adhesion spots compared to the PLL-coated glass (in particular at $c t=60 \mathrm{~s}$, see Figure $6 \mathrm{a}, \mathrm{b})$. In other words, on the nanotopographical surfaces the adhesion spots are exposed to higher forces. The decrease of high-force unbinding events on ns$\mathrm{ZrO}_{2}$ observed at $c t=240 \mathrm{~s}$, with respect to earlier $c t s$, is compatible with the general decrease of the $F_{a}$ (Figure $5 \mathrm{~b}$ ).

We point out how the increased occurrence of higher-force events (Figure 7 and 10) happens simultaneously with the drop of $N_{j}$ (Figure 6a), which depend on the availability of activated integrins (Figure 8), in the $\mathrm{ns}-\mathrm{ZrO}_{2}$ condition. This is peculiar, in particular because it happens during the critical time window for nascent adhesion growth and integrin clustering ${ }^{97}$. This temporal course of the nanotopography-specific adhesion dynamics could indicate that too small and/or too separated adhesion sites (critical thresholds for integrin clustering have been determined to be $\geq 60-70 \mathrm{~nm}$ ) disintegrate, due to exposure to excessively high forces. Instead, when the conditions are suitable, bigger clusters of integrin form and succeed to reinforce and mature 55,56,67,106,107 (Figure 11). These clusters might need to exceed at least the size of the minimal adhesion unit of a few integrins in sufficiently close, i.e. tens of nanometres, vicinity ${ }^{99,108}$; which is consistent with the appearance of the second peak at $120 \mathrm{pN}$.

These results are compatible with the dimensions of the nanotopographical features and the confinement action at the nanoscale, provided by the small contact area offered by the asperities of the nanostructures and the distance between them.

We have demonstrated previously that the PC12 cells are in contact only with the apical part of the nanotopographical asperities, which restricts the size of the adhesions sites to the nanometric level, and inhibits the maturation of bigger adhesion structures on a larger scale (see Figure 1a). Analyses of TEM images (an example in Figure 1a) showed that the contact areas between the cells and the asperities of the nanotopography (with a $r q=15 \mathrm{~nm}$ ) have an average width of $53.2 \pm 48.0$ nm (median: $40.4 \pm 21.6 \mathrm{~nm}$ ). Moreover, the distances (mean: $99.1 \pm 101.4 \mathrm{~nm}$, median: $60.4 \pm 30.4$ $\mathrm{nm}$ ) between the asperities of the disordered nanotopography effectively oscillate around the critical ligand spacing threshold $(\geq 60-70 \mathrm{~nm})^{44}$. The results reported in this work are consistent with these previous observations, and confirm, at the level of single binding events and at the $\mathrm{pN}$ scale, the crucial role of force loading in the molecular clutches in the nascent adhesions to accomplish nanometric spatial sensing of adhesion sites, reported recently by Oria et al. ${ }^{19}$. 


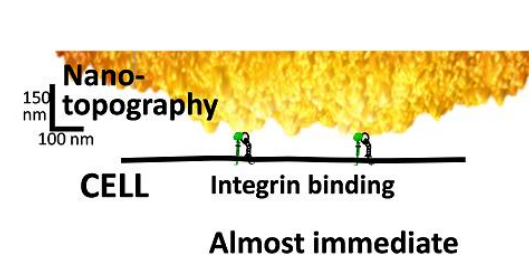

Almost immediate

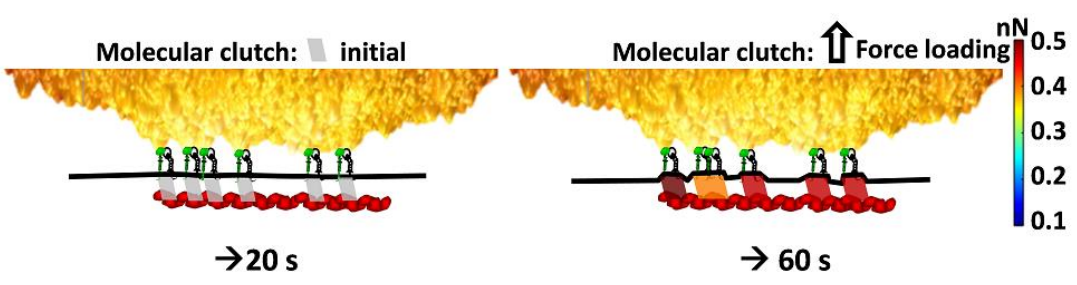

Nanotopography-sensitive

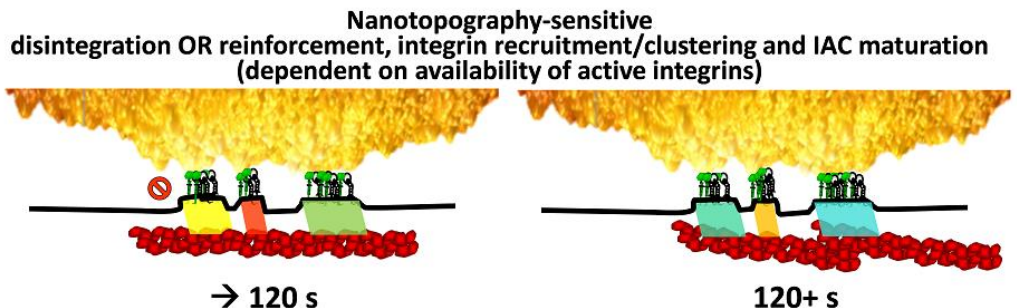

$\rightarrow 120 \mathrm{~s}$ $120+s$

Figure 11. This graphics is a visual representation of our actual experimental data integrated into a potential mechanism of nanotopography-sensitive force loading dynamics (left to right, and rowwise). The colours of the parallelogram icons (symbolising the engagement between the integrins and the actomyosin-generated forces, i.e. the molecular clutches) code for the force intensities measured by means of our approach at the different time points (see the bar on the right, compare with Fig. 7). The scheme illustrates the integrin recruitment/clustering, force distribution, molecular clutch reinforcement and integrin adhesion complex (IAC) maturation where the nanotopographical conditions are suitable, or disintegration of the initial structure due to excessive force exposure (because integrin recruitment and force distribution is insufficient) where the nanotopographical conditions are not suitable. The experiments with $\mathrm{Mn}^{2+}$ treatment furthermore showed that these dynamics are dependent on the availability of active integrins (see Fig. 8). The length scales on the left refers to the morphology of the nt-CP only; the other graphical objects (such as the integrins) are not in scale and also their number is symbolic to visualise the development.

\section{CONCLUSIONS}

Integrin-mediated mechanosensing and mechanotransduction is regulated by biophysical properties of the cellular microenvironment, such as e.g. the nanotopography of the ECM, as it influences the spatial and geometrical organisation of potential cellular adhesion sites ${ }^{7-10,29}$. However, a precise understanding of the spatiotemporal dynamics and molecular actions in the cell/microenvironment interface during adhesion is still elusive, because these events take place at the nanometre scale and involve $\mathrm{pN}$ range forces, whose exploration requires sophisticated 
methodologies. Moreover, an accurate control over the nanotopographical features of the microenvironment is essential, in order to systematically investigate and precisely assess the influence of the different nanotopographical motifs on the mechanotransductive process.

In this framework, we were able to study and quantify the impact of microenvironmental nanotopography on early cellular adhesion events by means of adhesion force spectroscopy based on novel colloidal probes mimicking the nanotopography of natural ECMs. Our approach merges the sensitivity of AFM-based force spectroscopy ${ }^{36,48}$ with the possibility of controlling the nanotopographical features of the ECM-mimicking substrate provided by Supersonic Cluster Beam Deposition $^{58}$.

Thanks to our innovative approach, we could detect nanotopography-specific modulations of the molecular force loading dynamics and integrin clustering at the level of single binding events, in the critical time window of nascent adhesion formation. Following this approach, we found that the availability of activated integrins is a critical regulatory factor for these nanotopography-dependent dynamics.

Our results are in agreement with the reported importance of force loading ${ }^{19}$ for cellular spatial sensing of the microenvironment, and integrin nanocluster bridging between adjacent (tens of $\mathrm{nm}$ ) adhesion arrays ${ }^{99}$.

In the future, we plan to exploit the fine control of the surface topography of the nanostructured colloidal probes to dissect in more detail the precise role of morphological properties (such as, e.g., roughness, asperities diameter/distance, or correlation length) in spatiotemporal cell adhesion dynamics, in particular focusing the attention on the clustering of integrin adhesion complexes ${ }^{44}$. Nanotopographical colloidal probes could also be used to examine how aberrations in components of the mechanotransductive machinery alter the force loading dynamics of cellular adhesion.

Additional features of nt-CPs make them suitable for the investigation of nanoscale phenomena of nanobiotechnological interest. Due to their large area, nt-CPs allows to optically probe the interaction interface, which is particular useful when using fluorescence microscopy and suitable staining of the actin cytoskeleton to image the focal adhesion spots. Moreover, nt-CPs could be used as nanotopographical templates for carrying out further functionalisations, for example by grafting to the corrugated surface biochemical moieties relevant to mechanotransduction, such as ligands, ECM motifs, etc. Apart from the cell biology framework, we think these probes have a good potential if used in physics of matter experiments, e.g. in the context of nanofriction ${ }^{109}$, DLVO theory ${ }^{81,110}$ or adhesive contact mechanics at disordered, nanostructured interfaces $^{111,112}$. 


\section{Acknowledgements}

We acknowledge the support of the European Union's Horizon 2020 research and innovation programme under the Marie Skłodowska-Curie grant agreement No 812772, project Phys2BioMed, and under the FET Open grant agreement No. 801126, project EDIT. PM and CS acknowledge support from the European Union FP7-NMP-2013-LARGE-7 "FutureNanoNeeds" programme.

We thank Francesca Borghi for support in the characterisation of CPs, Paolo Piseri for useful suggestions for the deposition of thin films by ion beam sputtering, and Mirko D'Urso for support in cell culture. We thank Dr. Stefano Marchesi and Dr. Stefania Marcotti for critical reading of the manuscript.

\section{Author contributions}

Conceptualisation: CS, AP; methodology - probe fabrication and characterisation: MC, AP, CP; methodology - cell culture and preparation: TD, CS; methodology - AFM spectroscopy: MC, TD, AP; data curation and analysis: MC, CS, AP; original draft writing: MC, CS, AP; draft reviewing and editing: MC, CS, AP, CL, PM; supervision: CL, PM, CS, AP; resources, funding and project administration: CL, PM, AP. Author contributions were allocated adopting the terminology of CRediT - Contributor Roles Taxonomy. 


\section{BIBLIOGRAPHY}

(1) Maurer, T.; Stoffel, M. H.; Belyaev, Y.; Stiefel, N. G.; Vidondo, B.; Küker, S.; Mogel, H.; Schäfer, B.; Balmer, J. Structural Characterization of Four Different Naturally Occurring Porcine Collagen Membranes Suitable for Medical Applications. PLOS ONE 2018, 13 (10), e0205027. https://doi.org/10.1371/journal.pone.0205027.

(2) Park, J.; Kim, D.-H.; Levchenko, A. Topotaxis: A New Mechanism of Directed Cell Migration in Topographic ECM Gradients. Biophys. J. 2018, 114 (6), 1257-1263. https://doi.org/10.1016/j.bpj.2017.11.3813.

(3) Lansky, Z.; Mutsafi, Y.; Houben, L.; Ilani, T.; Armony, G.; Wolf, S. G.; Fass, D. 3D Mapping of Native Extracellular Matrix Reveals Cellular Responses to the Microenvironment. J. Struct. Biol. X 2019, 1, 100002. https://doi.org/10.1016/j.yjsbx.2018.100002.

(4) Liliensiek, S. J.; Nealey, P.; Murphy, C. J. Characterization of Endothelial Basement Membrane Nanotopography in Rhesus Macaque as a Guide for Vessel Tissue Engineering. Tissue Eng. Part A 2009, 15 (9), 2643-2651. https://doi.org/10.1089/ten.tea.2008.0284.

(5) Tajerian, M.; Hung, V.; Nguyen, H.; Lee, G.; Joubert, L.-M.; Malkovskiy, A. V.; Zou, B.; Xie, S.; Huang, T.-T.; Clark, J. D. The Hippocampal Extracellular Matrix Regulates Pain and Memory after Injury. Mol. Psychiatry 2018, 23 (12), 2302-2313. https://doi.org/10.1038/s41380-0180209-z.

(6) Abrams, G. A.; Goodman, S. L.; Nealey, P. F.; Franco, M.; Murphy, C. J. Nanoscale Topography of the Basement Membrane Underlying the Corneal Epithelium of the Rhesus Macaque. Cell Tissue Res. 2000, 299 (1), 39-46. https://doi.org/10.1007/s004419900074.

(7) Dalby, M. J.; Gadegaard, N.; Oreffo, R. O. C. Harnessing Nanotopography and IntegrinMatrix Interactions to Influence Stem Cell Fate. Nat. Mater. 2014, 13 (6), 558-569. https://doi.org/10.1038/nmat3980.

(8) Gasiorowski, J. Z.; Murphy, C. J.; Nealey, P. F. Biophysical Cues and Cell Behavior: The Big Impact of Little Things. Annu. Rev. Biomed. Eng. 2013, 15, 155-176. https://doi.org/10.1146/annurev-bioeng-071811-150021.

(9) Young, J. L.; Holle, A. W.; Spatz, J. P. Nanoscale and Mechanical Properties of the Physiological Cell-ECM Microenvironment. Exp. Cell Res. 2016, 343 (1), 3-6. https://doi.org/10.1016/j.yexcr.2015.10.037.

(10) Crowder, S. W.; Leonardo, V.; Whittaker, T.; Papathanasiou, P.; Stevens, M. M. Material Cues as Potent Regulators of Epigenetics and Stem Cell Function. Cell Stem Cell 2016, 18 (1), 39-52. https://doi.org/10.1016/j.stem.2015.12.012. 
(11) DuFort, C. C.; Paszek, M. J.; Weaver, V. M. Balancing Forces: Architectural Control of Mechanotransduction. Nat. Rev. Mol. Cell Biol. 2011, 12 (5), 308-319. https://doi.org/10.1038/nrm3112.

(12) Sun, Z.; Guo, S. S.; Fässler, R. Integrin-Mediated Mechanotransduction. J Cell Biol 2016, jcb.201609037. https://doi.org/10.1083/jcb.201609037.

(13) Changede, R.; Sheetz, M. Integrin and Cadherin Clusters: A Robust Way to Organize Adhesions for Cell Mechanics. BioEssays 2017, 39 (1), n/a-n/a. https://doi.org/10.1002/bies.201600123.

(14) Gauthier, N. C.; Roca-Cusachs, P. Mechanosensing at Integrin-Mediated Cell-Matrix Adhesions: From Molecular to Integrated Mechanisms. Curr. Opin. Cell Biol. 2018, 50, 20-26. https://doi.org/10.1016/j.ceb.2017.12.014.

(15) Orré, T.; Rossier, O.; Giannone, G. The Inner Life of Integrin Adhesion Sites: From Single Molecules to Functional Macromolecular Complexes. Exp. Cell Res. 2019, 379 (2), 235-244. https://doi.org/10.1016/j.yexcr.2019.03.036.

(16) Kechagia, J. Z.; Ivaska, J.; Roca-Cusachs, P. Integrins as Biomechanical Sensors of the Microenvironment. Nat. Rev. Mol. Cell Biol. 2019, 1. https://doi.org/10.1038/s41580-0190134-2.

(17) Chighizola, M.; Dini, T.; Lenardi, C.; Milani, P.; Podestà, A.; Schulte, C. Mechanotransduction in Neuronal Cell Development and Functioning. Biophys. Rev. 2019. https://doi.org/10.1007/s12551-019-00587-2.

(18) Humphries, J. D.; Chastney, M. R.; Askari, J. A.; Humphries, M. J. Signal Transduction via Integrin Adhesion Complexes. Curr. Opin. Cell Biol. 2019, 56, 14-21. https://doi.org/10.1016/j.ceb.2018.08.004.

(19) Oria, R.; Wiegand, T.; Escribano, J.; Elosegui-Artola, A.; Uriarte, J. J.; Moreno-Pulido, C.; Platzman, I.; Delcanale, P.; Albertazzi, L.; Navajas, D.; et al. Force Loading Explains Spatial Sensing of Ligands by Cells. Nature 2017, $552 \quad$ (7684), 219. https://doi.org/10.1038/nature24662.

(20) Ingber, D. E. Mechanobiology and Diseases of Mechanotransduction. Ann. Med. 2003, 35 (8), 564-577. https://doi.org/10.1080/07853890310016333.

(21) Paszek, M. J.; Zahir, N.; Johnson, K. R.; Lakins, J. N.; Rozenberg, G. I.; Gefen, A.; ReinhartKing, C. A.; Margulies, S. S.; Dembo, M.; Boettiger, D.; et al. Tensional Homeostasis and the Malignant Phenotype. Cancer Cell 2005, 8 (3), 241-254. https://doi.org/10.1016/j.ccr.2005.08.010. 
(22) Jaalouk, D. E.; Lammerding, J. Mechanotransduction Gone Awry. Nat. Rev. Mol. Cell Biol. 2009, 10 (1), 63-73. https://doi.org/10.1038/nrm2597.

(23) Nebuloni, M.; Albarello, L.; Andolfo, A.; Magagnotti, C.; Genovese, L.; Locatelli, I.; Tonon, G.; Longhi, E.; Zerbi, P.; Allevi, R.; et al. Insight On Colorectal Carcinoma Infiltration by Studying Perilesional Extracellular Matrix. Sci. Rep. 2016, 6, 22522. https://doi.org/10.1038/srep22522.

(24) Vogel, V. Unraveling the Mechanobiology of Extracellular Matrix. Annu. Rev. Physiol. 2018, 80 (1), 353-387. https://doi.org/10.1146/annurev-physiol-021317-121312.

(25) Guck, J. Some Thoughts on the Future of Cell Mechanics. Biophys. Rev. 2019, 11 (5), 667-670. https://doi.org/10.1007/s12551-019-00597-0.

(26) Teo, B. K. K.; Wong, S. T.; Lim, C. K.; Kung, T. Y. S.; Yap, C. H.; Ramagopal, Y.; Romer, L. H.; Yim, E. K. F. Nanotopography Modulates Mechanotransduction of Stem Cells and Induces Differentiation through Focal Adhesion Kinase. ACS Nano 2013, 7 (6), 4785-4798. https://doi.org/10.1021/nn304966z.

(27) Carson, D.; Hnilova, M.; Yang, X.; Nemeth, C. L.; Tsui, J. H.; Smith, A. S. T.; Jiao, A.; Regnier, M.; Murry, C. E.; Tamerler, C.; et al. Nanotopography-Induced Structural Anisotropy and Sarcomere Development in Human Cardiomyocytes Derived from Induced Pluripotent Stem Cells. ACS Appl. Mater. Interfaces 2016, 8 (34), 21923-21932. https://doi.org/10.1021/acsami.5b11671.

(28) Yang, K.; Jung, K.; Ko, E.; Kim, J.; Park, K. I.; Kim, J.; Cho, S.-W. Nanotopographical Manipulation of Focal Adhesion Formation for Enhanced Differentiation of Human Neural Stem Cells. ACS Appl. Mater. Interfaces 2013, 5 (21), 10529-10540. https://doi.org/10.1021/am402156f.

(29) Chen, W.; Shao, Y.; Li, X.; Zhao, G.; Fu, J. Nanotopographical Surfaces for Stem Cell Fate Control: Engineering Mechanobiology from the Bottom. Nano Today 2014, 9 (6), 759-784. https://doi.org/10.1016/j.nantod.2014.12.002.

(30) Huang, J.; Grater, S. V.; Corbellini, F.; Rinck, S.; Bock, E.; Kemkemer, R.; Kessler, H.; Ding, J.; Spatz, J. P. Impact of Order and Disorder in RGD Nanopatterns on Cell Adhesion. Nano Lett. 2009, 9 (3), 1111-1116. https://doi.org/10.1021/nl803548b.

(31) Ngandu Mpoyi, E.; Cantini, M.; Reynolds, P. M.; Gadegaard, N.; Dalby, M. J.; SalmerónSánchez, M. Protein Adsorption as a Key Mediator in the Nanotopographical Control of Cell Behavior. ACS Nano 2016, 10 (7), 6638-6647. https://doi.org/10.1021/acsnano.6b01649.

(32) Mendes, P. M. Cellular Nanotechnology: Making Biological Interfaces Smarter. Chem. 
Soc. Rev. 2013, 42 (24), 9207-9218. https://doi.org/10.1039/C3CS60198F.

(33) Iskratsch, T.; Wolfenson, H.; Sheetz, M. P. Appreciating Force and Shape-the Rise of Mechanotransduction in Cell Biology. Nat. Rev. Mol. Cell Biol. 2014, 15 (12), 825-833. https://doi.org/10.1038/nrm3903.

(34) Li, L.; Eyckmans, J.; Chen, C. S. Designer Biomaterials for Mechanobiology. Nat. Mater. 2017, 16, 1164-1168. https://doi.org/10.1038/nmat5049.

(35) Darnell, M.; Mooney, D. J. Leveraging Advances in Biology to Design Biomaterials. Nat. Mater. 2017, 16 (12), 1178-1185. https://doi.org/10.1038/nmat4991.

(36) Krieg, M.; Fläschner, G.; Alsteens, D.; Gaub, B. M.; Roos, W. H.; Wuite, G. J. L.; Gaub, H. E.; Gerber, C.; Dufrêne, Y. F.; Müller, D. J. Atomic Force Microscopy-Based Mechanobiology. Nat. Rev. Phys. 2019, 1 (1), 41. https://doi.org/10.1038/s42254-018-0001-7.

(37) Amschler, K.; Erpenbeck, L.; Kruss, S.; Schön, M. P. Nanoscale Integrin Ligand Patterns Determine Melanoma Cell Behavior. ACS Nano 2014, 8 (9), 9113-9125. https://doi.org/10.1021/nn502690b.

(38) Chang, A. C.; Mekhdjian, A. H.; Morimatsu, M.; Denisin, A. K.; Pruitt, B. L.; Dunn, A. R. Single Molecule Force Measurements in Living Cells Reveal a Minimally Tensioned Integrin State. ACS Nano 2016, 10 (12), 10745-10752. https://doi.org/10.1021/acsnano.6b03314.

(39) Roberts, J. N.; Sahoo, J. K.; McNamara, L. E.; Burgess, K. V.; Yang, J.; Alakpa, E. V.; Anderson, H. J.; Hay, J.; Turner, L.-A.; Yarwood, S. J.; et al. Dynamic Surfaces for the Study of Mesenchymal Stem Cell Growth through Adhesion Regulation. ACS Nano 2016, 10 (7), 66676679. https://doi.org/10.1021/acsnano.6b01765.

(40) Radmacher, M. Studying the Mechanics of Cellular Processes by Atomic Force Microscopy. In Methods in Cell Biology; Cell Mechanics; Academic Press, 2007; Vol. 83, pp 347372. https://doi.org/10.1016/S0091-679X(07)83015-9.

(41) Schillers, H.; Rianna, C.; Schäpe, J.; Luque, T.; Doschke, H.; Wälte, M.; Uriarte, J. J.; Campillo, N.; Michanetzis, G. P. A.; Bobrowska, J.; et al. Standardized Nanomechanical Atomic Force Microscopy Procedure (SNAP) for Measuring Soft and Biological Samples. Sci. Rep. 2017, 7. https://doi.org/10.1038/s41598-017-05383-0.

(42) Puricelli, L.; Galluzzi, M.; Schulte, C.; Podestà, A.; Milani, P. Nanomechanical and Topographical Imaging of Living Cells by Atomic Force Microscopy with Colloidal Probes. Rev. Sci. Instrum. 2015, 86 (3), 033705. https://doi.org/10.1063/1.4915896.

(43) Stylianou, A.; Lekka, M.; Stylianopoulos, T. AFM Assessing of Nanomechanical Fingerprints for Cancer Early Diagnosis and Classification: From Single Cell to Tissue Level. 
Nanoscale 2018, 10 (45), 20930-20945. https://doi.org/10.1039/C8NR06146G.

(44) Schulte, C.; Rodighiero, S.; Cappelluti, M. A.; Puricelli, L.; Maffioli, E.; Borghi, F.; Negri, A.; Sogne, E.; Galluzzi, M.; Piazzoni, C.; et al. Conversion of Nanoscale Topographical Information of Cluster-Assembled Zirconia Surfaces into Mechanotransductive Events Promotes Neuronal Differentiation. J. Nanobiotechnology 2016, 14, 18. https://doi.org/10.1186/s12951-0160171-3.

(45) Ferraris, G. M. S.; Schulte, C.; Buttiglione, V.; De Lorenzi, V.; Piontini, A.; Galluzzi, M.; Podestà, A.; Madsen, C. D.; Sidenius, N. The Interaction between UPAR and Vitronectin Triggers Ligand-Independent Adhesion Signalling by Integrins. EMBO J. 2014, 33 (21), 24582472. https://doi.org/10.15252/embj.201387611.

(46) Schulte, C.; Ferraris, G. M. S.; Oldani, A.; Galluzzi, M.; Podestà, A.; Puricelli, L.; de Lorenzi, V.; Lenardi, C.; Milani, P.; Sidenius, N. Lamellipodial Tension, Not Integrin/Ligand Binding, Is the Crucial Factor to Realise Integrin Activation and Cell Migration. Eur. J. Cell Biol. 2016, 95 (1), 1-14. https://doi.org/10.1016/j.ejcb.2015.10.002.

(47) Dufrêne, Y. F.; Evans, E.; Engel, A.; Helenius, J.; Gaub, H. E.; Müller, D. J. Five Challenges to Bringing Single-Molecule Force Spectroscopy into Living Cells. Nat. Methods 2011, 8 (2), 123-127. https://doi.org/10.1038/nmeth0211-123.

(48) Müller, D. J.; Helenius, J.; Alsteens, D.; Dufrêne, Y. F. Force Probing Surfaces of Living Cells to Molecular Resolution. Nat. Chem. Biol. 2009, 5 (6), 383-390. https://doi.org/10.1038/nchembio.181.

(49) Friedrichs, J.; Legate, K. R.; Schubert, R.; Bharadwaj, M.; Werner, C.; Müller, D. J.; Benoit, M. A Practical Guide to Quantify Cell Adhesion Using Single-Cell Force Spectroscopy. Methods 2013, 60 (2), 169-178. https://doi.org/10.1016/j.ymeth.2013.01.006.

(50) Strohmeyer, N.; Bharadwaj, M.; Costell, M.; Fässler, R.; Müller, D. J. Fibronectin-Bound A5 $\beta 1$ Integrins Sense Load and Signal to Reinforce Adhesion in Less than a Second. Nat. Mater. 2017, 16 (12), 1262-1270. https://doi.org/10.1038/nmat5023.

(51) Li, F.; Redick, S. D.; Erickson, H. P.; Moy, V. T. Force Measurements of the Alpha5beta1 Integrin-Fibronectin Interaction. Biophys. J. 2003, 84 (2 Pt 1), 1252-1262. https://doi.org/10.1016/S0006-3495(03)74940-6.

(52) Taubenberger, A.; Cisneros, D. A.; Friedrichs, J.; Puech, P.-H.; Muller, D. J.; Franz, C. M. Revealing Early Steps of Alpha2beta1 Integrin-Mediated Adhesion to Collagen Type I by Using Single-Cell Force Spectroscopy. Mol. Biol. Cell 2007, 18 (5), 1634-1644. https://doi.org/10.1091/mbc.E06-09-0777. 
(53) Tulla, M.; Helenius, J.; Jokinen, J.; Taubenberger, A.; Müller, D. J.; Heino, J. TPA Primes Alpha2beta1 Integrins for Cell Adhesion. FEBS Lett. 2008, 582 (23-24), 3520-3524. https://doi.org/10.1016/j.febslet.2008.09.022.

(54) Bertoncini, P.; Chevalier, S. L.; Lavenus, S.; Layrolle, P.; Louarn, G. Early Adhesion of Human Mesenchymal Stem Cells on Ti02 Surfaces Studied by Single-Cell Force Spectroscopy Measurements. J. Mol. Recognit. 2012, 25 (5), 262-269. https://doi.org/10.1002/jmr.2193.

(55) Selhuber-Unkel, C.; López-García, M.; Kessler, H.; Spatz, J. P. Cooperativity in Adhesion Cluster Formation during Initial Cell Adhesion. Biophys. J. 2008, 95 (11), 5424-5431. https://doi.org/10.1529/biophysj.108.139584.

(56) Selhuber-Unkel, C.; Erdmann, T.; López-García, M.; Kessler, H.; Schwarz, U. S.; Spatz, J. P. Cell Adhesion Strength Is Controlled by Intermolecular Spacing of Adhesion Receptors. Biophys. J. 2010, 98 (4), 543-551. https://doi.org/10.1016/j.bpj.2009.11.001.

(57) Naganuma, T. The Relationship between Cell Adhesion Force Activation on Nano/Micro-Topographical Surfaces and Temporal Dependence of Cell Morphology. Nanoscale 2017, 9 (35), 13171-13186. https://doi.org/10.1039/C7NR04785A.

(58) Schulte, C.; Podestà, A.; Lenardi, C.; Tedeschi, G.; Milani, P. Quantitative Control of Protein and Cell Interaction with Nanostructured Surfaces by Cluster Assembling. Acc. Chem. Res. 2017, 50 (2), 231-239. https://doi.org/10.1021/acs.accounts.6b00433.

(59) Borghi, F.; Sogne, E.; Lenardi, C.; Podestà, A.; Merlini, M.; Ducati, C.; Milani, P. ClusterAssembled Cubic Zirconia Films with Tunable and Stable Nanoscale Morphology against Thermal Annealing. J. Appl. Phys. 2016, 120 (5), 055302. https://doi.org/10.1063/1.4960441. (60) Borghi, F.; Podestà, A.; Piazzoni, C.; Milani, P. Growth Mechanism of Cluster-Assembled Surfaces: From Submonolayer to Thin-Film Regime. Phys. Rev. Appl. 2018, 9 (4), 044016. https://doi.org/10.1103/PhysRevApplied.9.044016.

(61) Manicone, P. F.; Rossi Iommetti, P.; Raffaelli, L. An Overview of Zirconia Ceramics: Basic Properties and Clinical Applications. J. Dent. 2007, 35 (11), 819-826. https://doi.org/10.1016/j.jdent.2007.07.008.

(62) Borghi, F.; Sogne, E.; Lenardi, C.; Podestà, A.; Merlini, M.; Ducati, C.; Milani, P. ClusterAssembled Cubic Zirconia Films with Tunable and Stable Nanoscale Morphology against Thermal Annealing. J. Appl. Phys. 2016, 120 (5), 055302. https://doi.org/10.1063/1.4960441. (63) Schulte, C.; Ripamonti, M.; Maffioli, E.; Cappelluti, M. A.; Nonnis, S.; Puricelli, L.; Lamanna, J.; Piazzoni, C.; Podestà, A.; Lenardi, C.; et al. Scale Invariant Disordered Nanotopography Promotes Hippocampal Neuron Development and Maturation with 
Involvement of Mechanotransductive Pathways. Front. Cell. Neurosci. 2016, 10, 267. https://doi.org/10.3389/fncel.2016.00267.

(64) Maffioli, E.; Schulte, C.; Nonnis, S.; Grassi Scalvini, F.; Piazzoni, C.; Lenardi, C.; Negri, A.; Milani, P.; Tedeschi, G. Proteomic Dissection of Nanotopography-Sensitive Mechanotransductive Signalling Hubs That Foster Neuronal Differentiation in PC12 Cells. Front. Cell. Neurosci. 2017, 11. https://doi.org/10.3389/fncel.2017.00417.

(65) Arnold, M.; Cavalcanti-Adam, E. A.; Glass, R.; Blümmel, J.; Eck, W.; Kantlehner, M.; Kessler, H.; Spatz, J. P. Activation of Integrin Function by Nanopatterned Adhesive Interfaces. Chemphyschem Eur. J. Chem. Phys. Phys. Chem. 2004, 5 (3), 383-388. https://doi.org/10.1002/cphc.200301014.

(66) Cavalcanti-Adam, E. A.; Micoulet, A.; Blümmel, J.; Auernheimer, J.; Kessler, H.; Spatz, J. P. Lateral Spacing of Integrin Ligands Influences Cell Spreading and Focal Adhesion Assembly. Eur. J. Cell Biol. 2006, 85 (3), 219-224. https://doi.org/10.1016/j.ejcb.2005.09.011.

(67) Cavalcanti-Adam, E. A.; Volberg, T.; Micoulet, A.; Kessler, H.; Geiger, B.; Spatz, J. P. Cell Spreading and Focal Adhesion Dynamics Are Regulated by Spacing of Integrin Ligands. Biophys. J. 2007, 92 (8), 2964-2974. https://doi.org/10.1529/biophysj.106.089730.

(68) Schulte, C.; Lamanna, J.; Moro, A. S.; Piazzoni, C.; Borghi, F.; Chighizola, M.; Ortoleva, S.; Racchetti, G.; Lenardi, C.; Podestà, A.; et al. Neuronal Cells Confinement by Micropatterned Cluster-Assembled Dots with Mechanotransductive Nanotopography. ACS Biomater. Sci. Eng. 2018, 4 (12), 4062-4075. https://doi.org/10.1021/acsbiomaterials.8b00916.

(69) Nugroho, R. W. N.; Harjumäki, R.; Zhang, X.; Lou, Y.-R.; Yliperttula, M.; Valle-Delgado, J. J.; Österberg, M. Quantifying the Interactions between Biomimetic Biomaterials - Collagen I, Collagen IV, Laminin 521 and Cellulose Nanofibrils - by Colloidal Probe Microscopy. Colloids Surf. B Biointerfaces 2019, 173, 571-580. https://doi.org/10.1016/j.colsurfb.2018.09.073.

(70) Chièze, L.; Cigne, A. L.; Meunier, M.; Berquand, A.; Dedieu, S.; Devy, J.; Molinari, M. Quantitative Characterization of Single-Cell Adhesion Properties by Atomic Force Microscopy Using Protein-Functionalized Microbeads. J. Mol. Recognit. 2019, 32 (3), e2767. https://doi.org/10.1002/jmr.2767.

(71) Vasir, J. K.; Labhasetwar, V. Quantification of the Force of Nanoparticle-Cell Membrane Interactions and Its Influence on Intracellular Trafficking of Nanoparticles. Biomaterials 2008, 29 (31), 4244-4252. https://doi.org/10.1016/j.biomaterials.2008.07.020.

(72) Ong, Q. K.; Sokolov, I. Attachment of Nanoparticles to the AFM Tips for Direct Measurements of Interaction between a Single Nanoparticle and Surfaces. J. Colloid Interface 
Sci. 2007, 310 (2), 385-390. https://doi.org/10.1016/j.jcis.2007.02.010.

(73) Pyrgiotakis, G.; Blattmann, C. O.; Demokritou, P. Real-Time Nanoparticle-Cell Interactions in Physiological Media by Atomic Force Microscopy. ACS Sustain. Chem. Eng. 2014, 2 (7), 1681-1690. https://doi.org/10.1021/sc500152g.

(74) Leonenko, Z.; Finot, E.; Amrein, M. Adhesive Interaction Measured between AFM Probe and Lung Epithelial Type II Cells. Ultramicroscopy 2007, 107 (10), 948-953. https://doi.org/10.1016/j.ultramic.2007.02.036.

(75) Indrieri, M.; Podestà, A.; Bongiorno, G.; Marchesi, D.; Milani, P. Adhesive-Free Colloidal Probes for Nanoscale Force Measurements: Production and Characterization. Rev. Sci. Instrum. 2011, 82 (2), 023708. https://doi.org/10.1063/1.3553499.

(76) J.L. Hutter; J. Bechhoefer. Calibration of Atomic-force Microscope Tips. Rev. Sci. Instrum. 1993, 64 (7), 1868-1873. https://doi.org/10.1063/1.1143970.

(77) Butt, H.-J.; Jaschke, M. Calculation of Thermal Noise in Atomic Force Microscopy. Nanotechnology 1995, 6 (1), 1-7. https://doi.org/10.1088/0957-4484/6/1/001.

(78) Laurent, J.; Steinberger, A.; Bellon, L. Functionalized AFM Probes for Force Spectroscopy: Eigenmodes Shape and Stiffness Calibration through Thermal Noise Measurements. Nanotechnology 2013, 24 (22), 225504. https://doi.org/10.1088/0957$4484 / 24 / 22 / 225504$.

(79) Wegner, K.; Piseri, P.; Tafreshi, H. V.; Milani, P. Cluster Beam Deposition: A Tool for Nanoscale Science and Technology. J. Phys. Appl. Phys. 2006, 39 (22), R439. https://doi.org/10.1088/0022-3727/39/22/R02.

(80) Barborini, E.; Piseri, P.; Milani, P. A Pulsed Microplasma Source of High Intensity Supersonic Carbon Cluster Beams. J. Phys. Appl. Phys. 1999, 32 (21), L105. https://doi.org/10.1088/0022-3727/32/21/102.

(81) Borghi, F.; Scaparra, B.; Paternoster, C.; Milani, P.; Podestà, A. Electrostatic DoubleLayer Interaction at the Surface of Rough Cluster-Assembled Films: The Case of Nanostructured Zirconia. Langmuir 2018, $34 \quad$ (35), 10230-10242. https://doi.org/10.1021/acs.langmuir.8b01387.

(82) Galli, A.; Maffioli, E.; Sogne, E.; Moretti, S.; Cairano, E. S. D.; Negri, A.; Nonnis, S.; Norata, G. D.; Bonacina, F.; Borghi, F.; et al. Cluster-Assembled Zirconia Substrates Promote LongTerm Differentiation and Functioning of Human Islets of Langerhans. Sci. Rep. 2018, 8 (1), 117. https://doi.org/10.1038/s41598-018-28019-3.

(83) Weafer, P. P.; McGarry, J. P.; van Es, M. H.; Kilpatrick, J. I.; Ronan, W.; Nolan, D. R.; Jarvis, 
S. P. Stability Enhancement of an Atomic Force Microscope for Long-Term Force Measurement Including Cantilever Modification for Whole Cell Deformation. Rev. Sci. Instrum. 2012, 83 (9), 093709. https://doi.org/10.1063/1.4752023.

(84) Butt, H.-J.; Cappella, B.; Kappl, M. Force Measurements with the Atomic Force Microscope: Technique, Interpretation and Applications. Surf. Sci. Rep. 2005, 59 (1-6), 1-152. https://doi.org/10.1016/j.surfrep.2005.08.003.

(85) Janovjak, H.; Struckmeier, J.; Müller, D. J. Hydrodynamic Effects in Fast AFM SingleMolecule Force Measurements. Eur. Biophys. J. 2005, 34 (1), 91-96. https://doi.org/10.1007/s00249-004-0430-3.

(86) Carter, B. C.; Vershinin, M.; Gross, S. P. A Comparison of Step-Detection Methods: How Well Can You Do? Biophys. J. 2008, $94 \quad$ (1), 306-319. https://doi.org/10.1529/biophysj.107.110601.

(87) Opfer, J.; Gottschalk, K.-E. Identifying Discrete States of a Biological System Using a Novel Step Detection Algorithm. PLOS ONE 2012, 7 (11), e45896. https://doi.org/10.1371/journal.pone.0045896.

(88) Odorico, M.; Teulon, J.-M.; Berthoumieu, O.; Chen, S. -w. W.; Parot, P.; Pellequer, J.-L. An Integrated Methodology for Data Processing in Dynamic Force Spectroscopy of LigandReceptor Binding. Ultramicroscopy 2007, $107 \quad$ (10), 887-894. https://doi.org/10.1016/j.ultramic.2007.04.019.

(89) Podestà, A.; Borghi, F.; Indrieri, M.; Bovio, S.; Piazzoni, C.; Milani, P. Nanomanufacturing of Titania Interfaces with Controlled Structural and Functional Properties by Supersonic Cluster Beam Deposition. J. Appl. Phys. 2015, 118 (23), 234309. https://doi.org/10.1063/1.4937549.

(90) Gailite, L.; Scopelliti, P. E.; Sharma, V. K.; Indrieri, M.; Podestà, A.; Tedeschi, G.; Milani, P. Nanoscale Roughness Affects the Activity of Enzymes Adsorbed on Cluster-Assembled Titania Films. Langmuir 2014, 30 (20), 5973-5981. https://doi.org/10.1021/la500738u.

(91) Scopelliti, P. E.; Borgonovo, A.; Indrieri, M.; Giorgetti, L.; Bongiorno, G.; Carbone, R.; Podestà, A.; Milani, P. The Effect of Surface Nanometre-Scale Morphology on Protein Adsorption. PLOS ONE 2010, 5 (7), e11862. https://doi.org/10.1371/journal.pone.0011862.

(92) Bachhuka, A.; Hayball, J. D.; Smith, L. E.; Vasilev, K. The Interplay between Surface Nanotopography and Chemistry Modulates Collagen I and III Deposition by Human Dermal Fibroblasts. ACS Appl. Mater. Interfaces 2017, 9 (7), 5874-5884. https://doi.org/10.1021/acsami.6b15932. 
(93) Evans, E. A.; Calderwood, D. A. Forces and Bond Dynamics in Cell Adhesion. Science 2007, 316 (5828), 1148-1153. https://doi.org/10.1126/science.1137592.

(94) Sariisik, E.; Popov, C.; Müller, J. P.; Docheva, D.; Clausen-Schaumann, H.; Benoit, M. Decoding Cytoskeleton-Anchored and Non-Anchored Receptors from Single-Cell Adhesion Force Data. Biophys. J. 2015, 109 (7), 1330-1333. https://doi.org/10.1016/j.bpj.2015.07.048. (95) Mescola, A.; Vella, S.; Scotto, M.; Gavazzo, P.; Canale, C.; Diaspro, A.; Pagano, A.; Vassalli, M. Probing Cytoskeleton Organisation of Neuroblastoma Cells with Single-Cell Force Spectroscopy. J. Mol. Recognit. JMR 2012, 25 (5), 270-277. https://doi.org/10.1002/jmr.2173.

(96) Boettiger, D.; Wehrle-Haller, B. Integrin and Glycocalyx Mediated Contributions to Cell Adhesion Identified by Single Cell Force Spectroscopy. J. Phys. Condens. Matter Inst. Phys. J. 2010, 22 (19), 194101. https://doi.org/10.1088/0953-8984/22/19/194101.

(97) Vicente-Manzanares, M.; Horwitz, A. R. Adhesion Dynamics at a Glance. J. Cell Sci. 2011, 124 (23), 3923-3927. https://doi.org/10.1242/jcs.095653.

(98) Changede, R.; Xu, X.; Margadant, F.; Sheetz, M. P. Nascent Integrin Adhesions Form on All Matrix Rigidities after Integrin Activation. Dev. Cell 2015, 35 (5), 614-621. https://doi.org/10.1016/j.devcel.2015.11.001.

(99) Changede, R.; Cai, H.; Wind, S. J.; Sheetz, M. P. Integrin Nanoclusters Can Bridge Thin Matrix Fibres to Form Cell-Matrix Adhesions. Nat. Mater. 2019, 1-10. https://doi.org/10.1038/s41563-019-0460-y.

(100) Sun, Z.; Martinez-Lemus, L. A.; Trache, A.; Trzeciakowski, J. P.; Davis, G. E.; Pohl, U.; Meininger, G. A. Mechanical Properties of the Interaction between Fibronectin and Alpha5beta1-Integrin on Vascular Smooth Muscle Cells Studied Using Atomic Force Microscopy. Am. J. Physiol. Heart Circ. Physiol. 2005, 289 (6), H2526-2535. https://doi.org/10.1152/ajpheart.00658.2004.

(101) Kong, F.; García, A. J.; Mould, A. P.; Humphries, M. J.; Zhu, C. Demonstration of Catch Bonds between an Integrin and Its Ligand. J. Cell Biol. 2009, 185 (7), 1275-1284. https://doi.org/10.1083/jcb.200810002.

(102) Wang, X.; Ha, T. Defining Single Molecular Forces Required to Activate Integrin and Notch Signaling. Science 2013, $340 \quad$ (6135), 991-994. https://doi.org/10.1126/science.1231041.

(103) Liu, Y.; Yehl, K.; Narui, Y.; Salaita, K. Tension Sensing Nanoparticles for MechanoImaging at the Living/Nonliving Interface. J. Am. Chem. Soc. 2013, 135 (14), 5320-5323. https://doi.org/10.1021/ja401494e. 
(104) Galior, K.; Liu, Y.; Yehl, K.; Vivek, S.; Salaita, K. Titin-Based Nanoparticle Tension Sensors Map High-Magnitude Integrin Forces within Focal Adhesions. Nano Lett. 2016, 16 (1), 341-348. https://doi.org/10.1021/acs.nanolett.5b03888.

(105) Yao, M.; Goult, B. T.; Chen, H.; Cong, P.; Sheetz, M. P.; Yan, J. Mechanical Activation of Vinculin Binding to Talin Locks Talin in an Unfolded Conformation. Sci. Rep. 2014, 4, 4610. https://doi.org/10.1038/srep04610.

(106) Arnold, M.; Cavalcanti-Adam, E. A.; Glass, R.; Blümmel, J.; Eck, W.; Kantlehner, M.; Kessler, H.; Spatz, J. P. Activation of Integrin Function by Nanopatterned Adhesive Interfaces. Chemphyschem Eur. J. Chem. Phys. Phys. Chem. 2004, 5 (3), 383-388. https://doi.org/10.1002/cphc.200301014.

(107) Cavalcanti-Adam, E. A.; Micoulet, A.; Blümmel, J.; Auernheimer, J.; Kessler, H.; Spatz, J. P. Lateral Spacing of Integrin Ligands Influences Cell Spreading and Focal Adhesion Assembly. Eur. J. Cell Biol. 2006, 85 (3), 219-224. https://doi.org/10.1016/j.ejcb.2005.09.011.

(108) Schvartzman, M.; Palma, M.; Sable, J.; Abramson, J.; Hu, X.; Sheetz, M. P.; Wind, S. J. Nanolithographic Control of the Spatial Organization of Cellular Adhesion Receptors at the Single-Molecule Level. Nano Lett. 2011, 11 (3), 1306-1312. https://doi.org/10.1021/nl104378f.

(109) Bhushan, B.; Sundararajan, S. Micro/Nanoscale Friction and Wear Mechanisms of Thin Films Using Atomic Force and Friction Force Microscopy. Acta Mater. 1998, 46 (11), 37933804. https://doi.org/10.1016/S1359-6454(98)00062-7.

(110) Borghi, F.; Vyas, V.; Podestà, A.; Milani, P. Nanoscale Roughness and Morphology Affect the IsoElectric Point of Titania Surfaces. PLOS ONE 2013, 8 (7), e68655. https://doi.org/10.1371/journal.pone.0068655.

(111) Deng, W.; Kesari, H. Depth-Dependent Hysteresis in Adhesive Elastic Contacts at Large Surface Roughness. Sci. Rep. 2019, 9 (1), 1-12. https://doi.org/10.1038/s41598-018-38212Z.

(112) Kesari, H.; Doll, J. C.; Pruitt, B. L.; Cai, W.; Lew, A. J. Role of Surface Roughness in Hysteresis during Adhesive Elastic Contact. Philos. Mag. Lett. 2010, 90 (12), 891-902. https://doi.org/10.1080/09500839.2010.521204. 


\section{Adhesion force spectroscopy with nanostructured colloidal probes reveals nanotopography-dependent early mechanotransductive interactions at the cell membrane level}

M. Chighizola, A. Previdi, T. Dini, C. Piazzoni, C. Lenardi, P. Milani, C. Schulte* and A. Podestä

C.I.Ma.I.Na. and Dipartimento di Fisica "Aldo Pontremoli", Università degli Studi di Milano, via Celoria 16, 20133 Milan, Italy.

*Corresponding authors: alessandro.podesta@mi.infn.it; carsten.schulte@ unimi.it

\section{SUPPORTING INFORMATION}

\section{Contents}

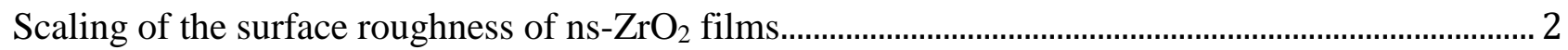

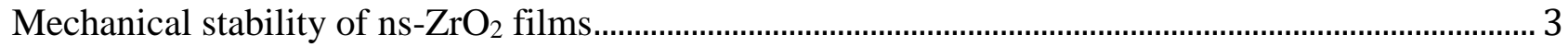

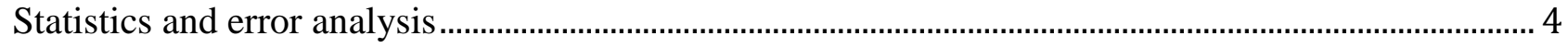

Force curves during contact ............................................................................................................... 5

Dependence of the adhesion force on the contact times, with the contribution of the tethers ............. 6

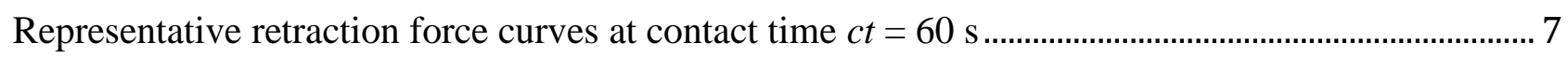

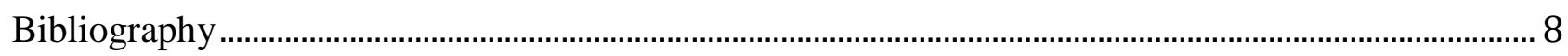




\section{Scaling of the surface roughness of ns- $\mathrm{ZrO}_{2}$ films}

To characterise the growth mechanism of ns- $\mathrm{ZrO}_{2}$ films on colloidal probes (CPs), we dispersed the glass spheres on a flat glass microscopy slide, and deposited ns- $\mathrm{ZrO}_{2}$ films varying the deposition times. We then imaged the coated CP surfaces by AFM in Tapping Mode (probe model: NCHV, Bruker), with relative scan speed of the tip $\mathrm{v}_{\mathrm{scan}}=2 \mu \mathrm{m} / \mathrm{s}$, and we measured the rms roughness $r_{q}$. The film thickness $h$ was measured on the flat glass surface, in a region close to a sphere, by imaging the $\mathrm{ns}-\mathrm{ZrO}_{2}$ film across a sharp step produced by masking the substrate during deposition. By applying a linear regression on a loglog scale to the $r_{q}$ versus $h$ curve (see Figure $\mathrm{S} 1$ ), the value of the growth exponent $b$ can be determined as the slope of the curve, according to the equation $r_{q} \sim h^{b}$.

According to previous results ${ }^{1-3}$, the $b$ parameter of the cluster-assembled $\mathrm{ZrO}_{2}$ thin films grown on flat substrates is $b=0.368 \pm 0.001$ on silicon, or $b=0.31 \pm 0.09$ on glass coated with a monomolecular PAcrAm-g-(PMOXA, $\left.\mathrm{NH}_{2}, \mathrm{Si}\right)$ layer ${ }^{4}$. These values are compatible with the prediction of the ballistic deposition growth model $(b=0.32-0.25)$, which assumes that clusters impinge with a direction perpendicular to the plane of the substrate, and they do not diffuse significantly upon landing ${ }^{5-7}$. Higher values can be found when the impinging particles possess a distribution of size and different sticking probabilities.

On nt-CPs, we found $b=0.314 \pm 0.017$, in agreement with the value measured on flat substrates. Therefore, the curvature of the nt-CPs did not influence the growth exponent.

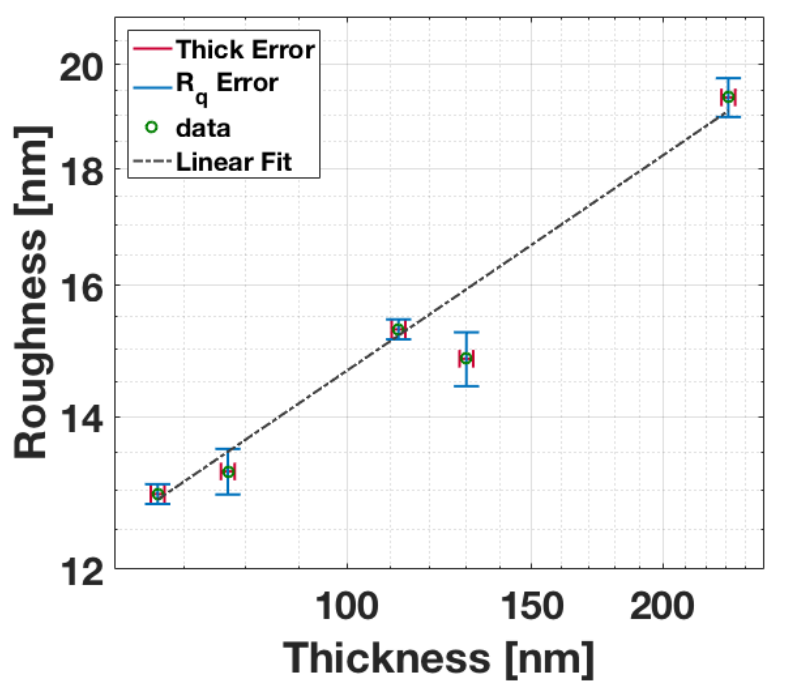

Figure S1. Scaling of the rms roughness $r_{q}$ of $n s-\mathrm{ZrO}_{2}$ film (i.e. roughness) on the nt-CPs. 


\section{Mechanical stability of ns- $\mathrm{ZrO}_{2}$ films}

To test the mechanical stability of the nanostructured coating we used a stiff AFM tapping mode probe (force constant $\mathrm{K}=50.4 \mathrm{~N} / \mathrm{m}$ ) to apply high forces on the thin film, in order to record at witch forces rupture events between $\mathrm{ZrO} 2$ nanoparticles take place.

An example of the force curve (FC) with the rupture events detected is shown in Figure S2a, while the rupture forces measured are represented in Figure S2b. Rupture forces are clustered around specific values and it is possible that the higher forces events represent cascade rupture events, where groups of nanoparticles simultaneously detach, while the lower forces represent the tip slipping across a nanoparticle, or small nanoparticles detaching from low-attachment points. The lowest rupture force detected is around $\mathrm{F} \sim 70 \mathrm{nN}$, that is almost 25 times larger than the highest force measured during the force spectroscopy experiment.

Furthermore, we scanned in Tapping Mode the surface of the contact region of an nt-CP after a whole day of force spectroscopy experiments. The image obtained is shown in Figure S2c, after subtraction of the spherical curvature in order to highlight the morphological details at the nanoscale. The granularity of the surface due to the presence of the ns- $\mathrm{ZrO} 2$ thin film is clearly evident.
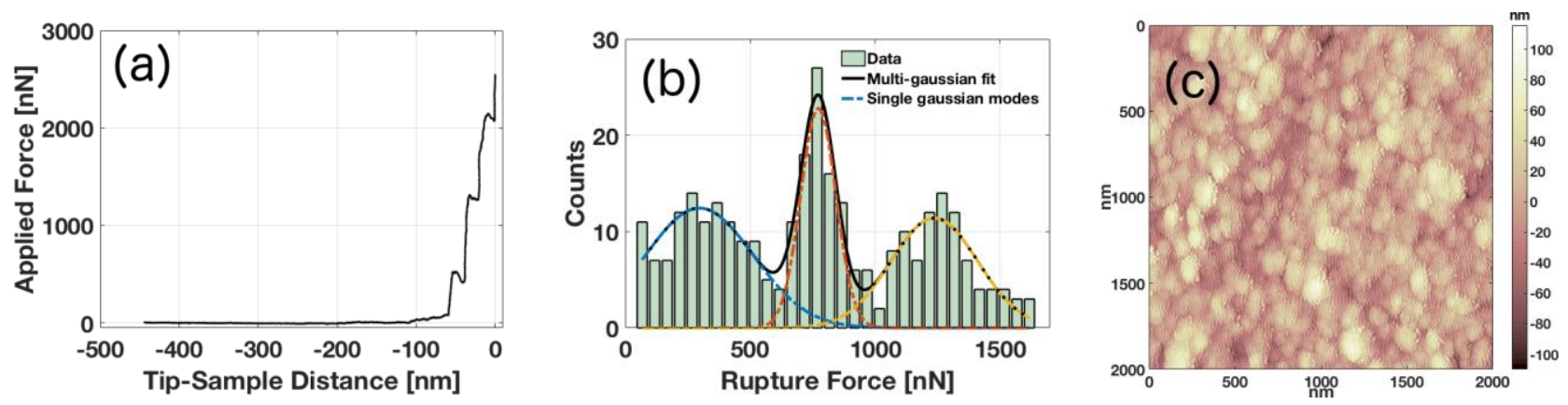

Figure S2. (a) Representative FC with three rupture events detected; (b) distribution of the rupture event forces from all FCs, with multi-gaussian fit highlighted; (c) scan of the contact surface of an $n t$-CP after force spectroscopy experiment. 


\section{Statistics and error analysis}

For each observable $\psi_{F C s}$ extracted by each force curve (FC) a mean value $\psi_{\text {cell }}$ was evaluated for each cell. The error $\sigma_{\text {cell }}$ associated to $\psi_{\text {cell }}$ was obtained by summing in quadrature the standard deviation of the mean $\sigma_{\psi}$ of the results coming from the single FCs and an estimated instrumental error $\sigma_{\text {instrum }}\left(\sigma_{\text {instrum }} / \psi=3 \%\right)^{8}$ :

$$
\psi_{\text {cell }}=\frac{\sum_{i}^{n} \psi_{F C S}}{n}
$$

where $n$ is the number of force curves per each cell,

$$
\sigma_{\text {cell }}=\sqrt{\sigma_{\psi}^{2}+\sigma_{\text {instrum }}^{2}}
$$

The final mean value $\psi_{\text {mean }}$ representative of the cell population behaviour in a given condition was evaluated as:

$$
\psi_{\text {mean }}=\frac{\sum_{i}^{n} \psi_{\text {cell }}}{N}
$$

where $N$ is the number of cells investigated for the given condition.

The final error $\sigma_{\text {mean }}$ associated to $\psi_{\text {mean }}$ was calculated by summing in quadrature the propagated error of the mean $\sigma_{s}$ and the standard deviation of the mean of the singles cell values $\psi$ cell:

$$
\sigma_{\text {mean }}=\sqrt{\sigma_{\text {std }}^{2}+\sigma_{\mathrm{s}}^{2}}
$$

where

$$
\sigma_{\mathrm{s}}=\frac{1}{N} \sqrt{\sum_{i} \sigma_{\text {cell }}^{2}}, \sigma_{\text {std }}=\sqrt{\frac{\sum_{i}^{n}\left(\psi_{\text {cell }, i}-\psi_{\text {fin }}\right)^{2}}{N}}
$$


bioRxiv preprint doi: https://doi.org/10.1101/2020.01.02.892919; this version posted March 5, 2020. The copyright holder for this preprint (which was not certified by peer review) is the author/funder, who has granted bioRxiv a license to display the preprint in perpetuity. It is made available under aCC-BY-ND 4.0 International license.

\section{Force curves during contact}

To test the stability of the Z-piezo upon contact of the CP with the sample in close-loop mode, we recorded the cantilever deflection as a function of the contact time $t$, up to $t=240 \mathrm{~s}$.

The time-dependent deflection is shown in Figure S3. On a stiff substrate, a smooth drift is observed ( 10nm in $240 \mathrm{~s})$, corresponding to a maximum variation of the applied force of approximately $0.5 \mathrm{nN}$ after 240s. On the cell surface, a similar drift is observed superimposed to small and slow (tens of $\mathrm{nm}$ in tens of seconds) fluctuations, due to the adjustment of the cell below the probe, probably accompanied by internal reorganisation of the cytoskeleton ${ }^{9}$.

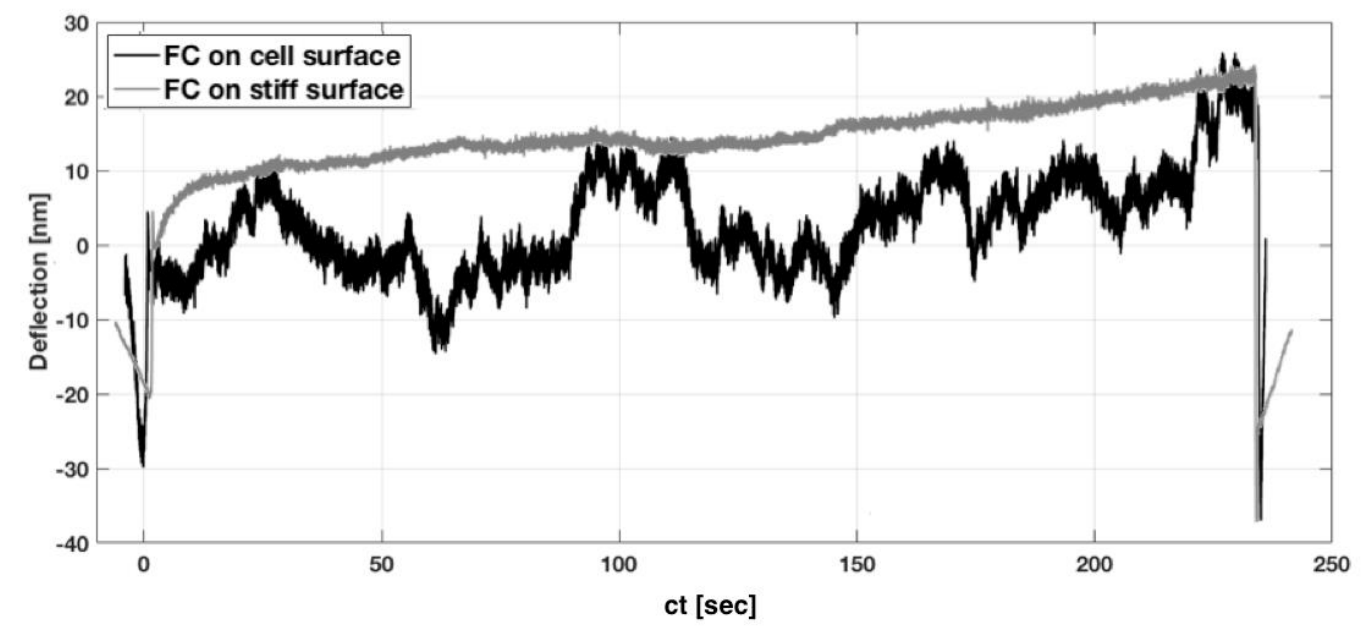

Figure S3. Representative deflection versus contact time curves. 
bioRxiv preprint doi: https://doi.org/10.1101/2020.01.02.892919; this version posted March 5, 2020. The copyright holder for this preprint (which was not certified by peer review) is the author/funder, who has granted bioRxiv a license to display the preprint in perpetuity. It is made available under aCC-BY-ND 4.0 International license.

Dependence of the adhesion force on the contact times, with the contribution of the tethers

The evaluation of the tethers contribution to the total adhesion force $F_{a}$ was evaluated as follow: for each contact time, the mean value of the tethers unbinding force has been evaluated and multiplied by the mean number of tethers $N_{t}$ per FC, to obtain the tether background adhesion value.

The contribution of the tethers then has been subtracted from the adhesion force $F_{a}$, in order to calculate the contribution of the jumps. The obtained total jump adhesion force was eventually divided by the mean number of jumps $N_{j}$, in order to calculate the mean adhesion force per jump presented in Figures 7,8 of the main text.

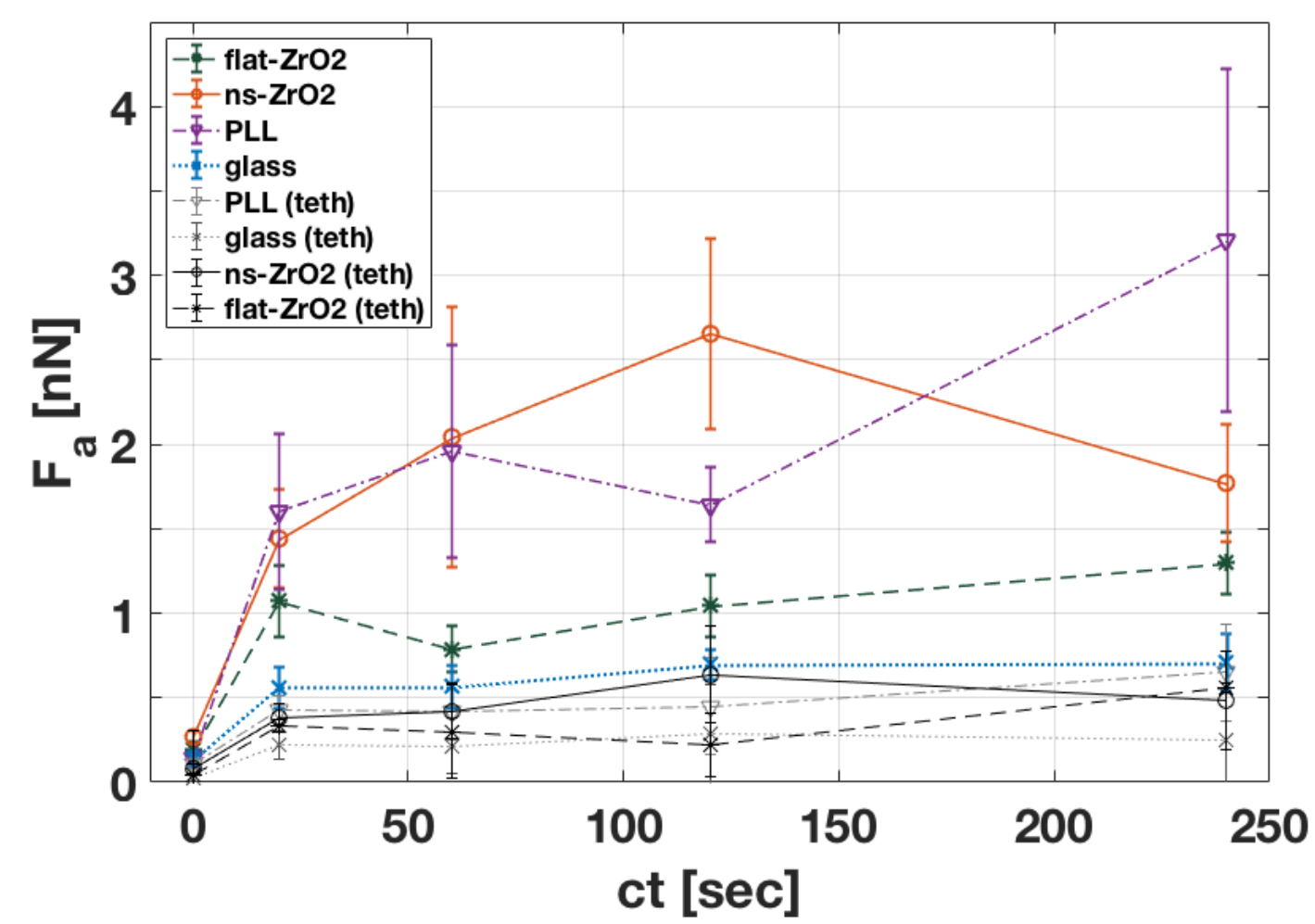

Figure S4. Dependence of the adhesion force on the contact times as in Figure 5; in addition, the contribution of the tethers is shown. 


\section{Representative retraction force curves at contact time $c t=60 \mathrm{~s}$}

We show representative of FCs of the adhesive behaviour of the cells on the different surfaces for contact time $c t=60$ s with jump events highlighted by black arrows.

It is possible to observe the differences in the adhesion force $F_{a}$, work of detachment $W$, and number of jumps $N_{j}$, respectively. In particular, it can be seen how the adhesion on the ns- $\mathrm{ZrO}_{2}$ surface reaches values compatible to the adhesion on the PLL, even in the presence of much less detachment events.
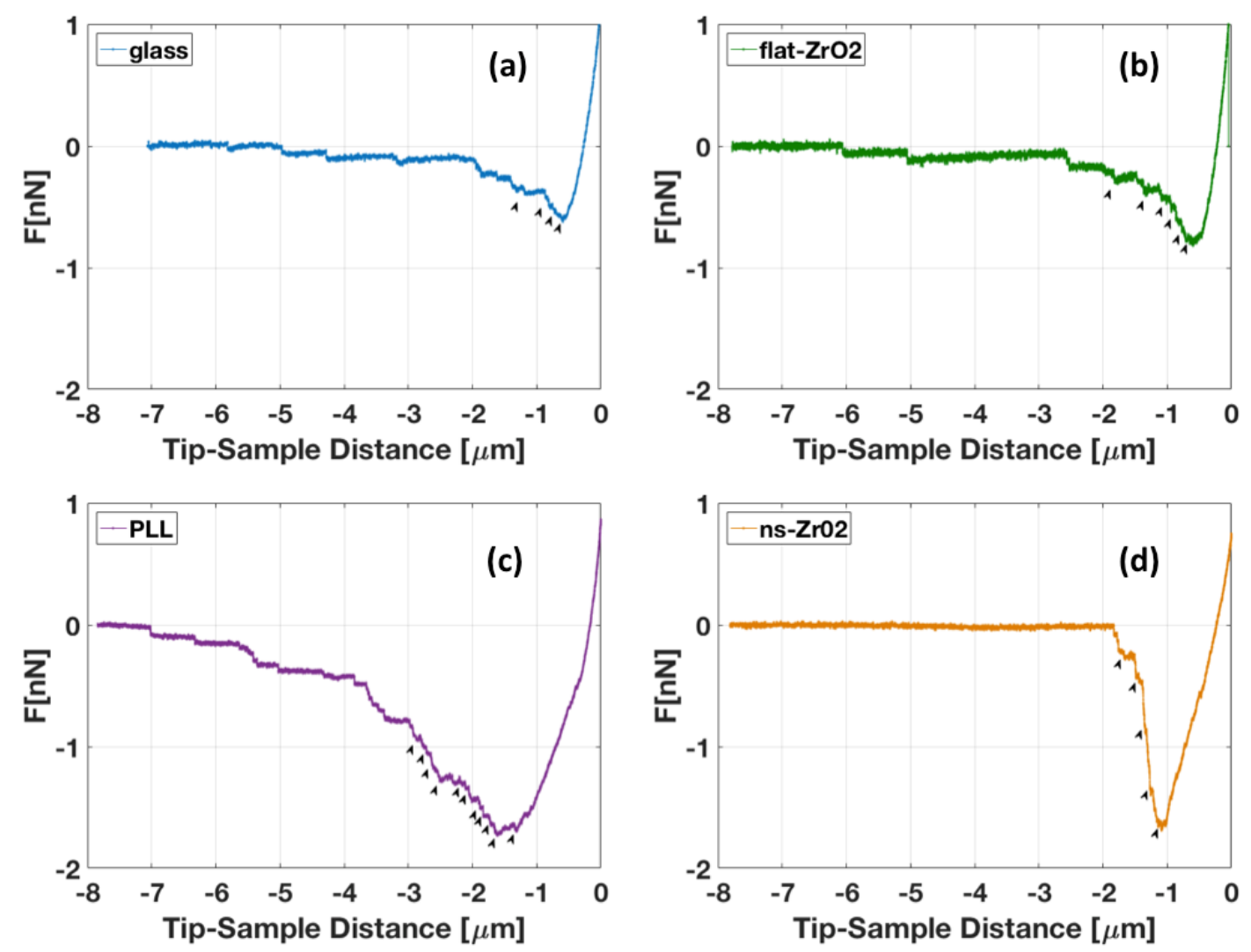

Figure S5. Representative FCs at ct=60 s for each condition: (a) glass, (b) flat-ZrO $\mathrm{Z}_{2}$ (c) PLL, (d) $n s-\mathrm{ZrO}_{2}$. 


\section{Bibliography}

(1) Borghi, F.; Podestà, A.; Piazzoni, C.; Milani, P. Growth Mechanism of Cluster-Assembled Surfaces: From Submonolayer to Thin-Film Regime. Phys. Rev. Appl. 2018, 9 (4), 044016. https://doi.org/10.1103/PhysRevApplied.9.044016.

(2) Borghi, F.; Sogne, E.; Lenardi, C.; Podestà, A.; Merlini, M.; Ducati, C.; Milani, P. ClusterAssembled Cubic Zirconia Films with Tunable and Stable Nanoscale Morphology against Thermal Annealing. J. Appl. Phys. 2016, 120 (5), 055302. https://doi.org/10.1063/1.4960441.

(3) Podestà, A.; Borghi, F.; Indrieri, M.; Bovio, S.; Piazzoni, C.; Milani, P. Nanomanufacturing of Titania Interfaces with Controlled Structural and Functional Properties by Supersonic Cluster Beam Deposition. J. Appl. Phys. 2015, 118 (23), 234309. https://doi.org/10.1063/1.4937549.

(4) Schulte, C.; Lamanna, J.; Moro, A. S.; Piazzoni, C.; Borghi, F.; Chighizola, M.; Ortoleva, S.; Racchetti, G.; Lenardi, C.; Podestà, A.; et al. Neuronal Cells Confinement by Micropatterned Cluster-Assembled Dots with Mechanotransductive Nanotopography. ACS Biomater. Sci. Eng. 2018, 4 (12), 4062-4075. https://doi.org/10.1021/acsbiomaterials.8b00916.

(5) Barabási, A.-L.; Stanley, H. E. Fractal Concepts in Surface Growth by A.- L. Barabási /core/books/fractal-concepts-in-surface-growth/0D9076FC287B60B2B1126BB165112F13 (accessed Sep 4, 2019). https://doi.org/10.1017/CBO9780511599798.

(6) Family, F.; Vicsek, T. Scaling of the Active Zone in the Eden Process on Percolation Networks and the Ballistic Deposition Model. J. Phys. Math. Gen. 1985, 18 (2), L75-L81. https://doi.org/10.1088/0305-4470/18/2/005.

(7) Robbins, M. O.; Cieplak, M.; Ji, H.; Koiller, B.; Martys, N. Growth in Systems with Quenched Disorder. In Growth Patterns in Physical Sciences and Biology; Garcia-Ruiz, J. M., Louis, E., Meakin, P., Sander, L. M., Eds.; NATO ASI Series; Springer US: Boston, MA, 1993; pp 6575. https://doi.org/10.1007/978-1-4615-2852-4_8.

(8) Puricelli, L.; Galluzzi, M.; Schulte, C.; Podestà, A.; Milani, P. Nanomechanical and Topographical Imaging of Living Cells by Atomic Force Microscopy with Colloidal Probes. Rev. Sci. Instrum. 2015, 86 (3), 033705. https://doi.org/10.1063/1.4915896. 